Article

\title{
Changes of Chinese Coastal Regions Induced by Land Reclamation as Revealed through TanDEM-X DEM and InSAR Analyses
}

\author{
Maochuan Tang ${ }^{1,2,3}$, Qing Zhao ${ }^{1,2,3, * \mathbb{D}}$, Antonio Pepe ${ }^{4} \mathbb{D}$, Adam Thomas Devlin ${ }^{5,6,7}$, Francesco Falabella ${ }^{4,8,9} \mathbb{( \mathbb { D }}$, \\ Chengfang Yao ${ }^{1,2,3}$ and Zhengjie $\mathrm{Li}^{1,2,3}$
}

1 Key Laboratory of Geographical Information Science, Ministry of Education, East China Normal University, Shanghai 200241, China; 51193901043@stu.ecnu.edu.cn (M.T.); 51203901043@stu.ecnu.edu.cn (C.Y.); 51203901076@stu.ecnu.edu.cn (Z.L.)

2 Institute of Eco-Chongming (I.E.C.), East China Normal University, Shanghai 202162, China

3 School of Geographic Sciences, East China Normal University, Shanghai 200241, China

4 Institute for Electromagnetic Sensing of the Environment (IREA), Italian National Research Council, 328, Diocleziano, 80124 Napoli, Italy; pepe.a@irea.cnr.it (A.P.); francesco.falabella@unibas.it (F.F.)

5 Key Laboratory of Poyang Lake Wetland and Watershed Research of Ministry of Education, Nanchang 330022, China; atdevlin@jxnu.edu.cn

6 School of Geography and Environment, Jiangxi Normal University, Nanchang 330022, China

7 Institute of Space and Earth Information Science, The Chinese University of Hong Kong, Shatin, Hong Kong, China

8 Institute of Methodologies for Environmental Analysis (IMAA), Italian National Research Council, Tito Scalo, 85050 Potenza, Italy

9 School of Engineering, University of Basilicata, 85100 Potenza, Italy

* Correspondence: qzhao@geo.ecnu.edu.cn; Tel.: +86-21-62224459

Citation: Tang, M.; Zhao, Q.; Pepe, A.; Devlin, A.T.; Falabella, F.; Yao, C.; $\mathrm{Li}, \mathrm{Z}$. Changes of Chinese Coastal Regions Induced by Land Reclamation as Revealed through TanDEM-X DEM and InSAR Analyses. Remote Sens. 2022, 14, 637 https://doi.org/10.3390/rs14030637

Academic Editor: Gilda Schirinzi

Received: 6 December 2021

Accepted: 24 January 2022

Published: 28 January 2022

Publisher's Note: MDPI stays neutral with regard to jurisdictional claims in published maps and institutional affiliations.

Copyright: (C) 2022 by the authors. Licensee MDPI, Basel, Switzerland. This article is an open access article distributed under the terms and conditions of the Creative Commons Attribution (CC BY) license (https:// creativecommons.org/licenses/by/ $4.0 /)$.

\begin{abstract}
Chinese coastal topography has changed significantly over the last two decades due to human actions such as the development of extensive land reclamation projects. Newly-reclaimed lands typically have low elevations $(<10 \mathrm{~m})$ and often experience severe ground subsidence. These conditions, combined with the more frequent occurrence of extreme sea-level events amplified by global climate change, lead to an increased risk of flooding of coastal regions. This work focuses on twelve Chinese coastal areas that underwent significant changes from 2000 to 2015 in their environments, correlated to relevant land reclamation projects. First, the ground changes between 2000 and 2015 were roughly computed by comparing the TanDEM-X and the Shuttle Radar Topography Mission (SRTM) digital elevation models of the investigated areas. These results indicate that six of the analyzed coastal zones have reclaimed more than $200 \mathrm{~km}^{2}$ of new lands from 2000 to 2015, with five of them in northern China. Second, we focused specifically on the city of Shanghai, and characterized the risk of flood in this area. To this purpose, two independent sets of synthetic aperture radar (SAR) data collected at the X- and C-band through the COSMO-SkyMed (CSK) and the European Copernicus Sentinel-1 (S-1) sensors were exploited. We assumed that the still extreme seawater depth is chi-square distributed, and estimated the probability of waves overtopping the coast. We also evaluated the impact on the territory of potential extreme flood events by counting the number of very-coherent objects (at most anthropic, such as buildings and public infrastructures) that could be seriously affected by a flood. To forecast possible inundation patterns, we used the LISFLOOD-FP hydrodynamic model. Assuming that an extreme event destroyed a given sector of the coastline, we finally computed the extent of the flooded areas and quantified its impact in terms of coherent structures potentially damaged by the inundation. Experimental results showed that two coastline segments located in the southern districts of Shanghai, where the seawalls height is lower, had the highest probability of wave overtopping and the most significant density of coherent objects potentially subjected to severe flood impacts.
\end{abstract}

Keywords: land reclamation; TanDEM-X DEM; floodplain inundation; InSAR 


\section{Introduction}

Coastal zones are transitional regions connecting ocean and land systems containing highly concentrated human activities [1]. The rapid urbanization of coastal cities has yielded a scarcity of suitable space for development. Land reclamation is a common worldwide practice [2] as it can be an efficient way to mitigate land-use pressure. Around 52\% of the world's megacities with populations greater than 10 million are located in coastal zones, and many of them have carried out some measure of coastal reclamation projects [3]. In China, coastal regions are essential for social-economic development. From 1991 to 2015, over $6418.9 \mathrm{~km}^{2}$ of new lands were reclaimed from the sea [4], which have been utilized for agriculture (e.g., cultivation, aquaculture, and salt pan), industry (e.g., wharves and factories), and urban development (e.g., residences) [5]. Such reclamation projects have played a significant role in the socio-economic development of China [6]. Previous studies on the coastal evolution of China have mainly focused on calculating and analyzing the changes in coastline length, coastline types, reclamation areas, and reclamation intensity (i.e., the reclamation area per kilometer of coastline) $[4,7,8]$. Before the advent of remote sensing technologies $[9,10]$, the length and location of coastlines were obtained from historical maps or field survey results, geomorphological maps [11], or historical documents that recorded land reclamation projects [12]. Currently, optical remote sensing images at multiple time scales are the main data source for coastal evolution research. Free and open access image archives such as Landsat, which have a long record and are geometrically and radiometrically consistent, are often employed [13-16]. Established methods of extracting coastlines include manual and automatic interpretation [17]. Manual interpretation is widely used, and its accuracy is determined by the spatial resolution of the images [18]. Automatic coastline delineation involves image segmentation [19], which detects the landsea boundary. Automatic interpretation methods include threshold segmentation $[17,20]$, edge detection [21], object-oriented approaches [22], and active contour models [23]. Once the spatial and temporal changes of the coastline are determined, the area and rate of coastal erosion/accretion can also be obtained. However, the traditional methods applied for coastal evolution monitoring rely on identifying the land-sea boundary, extracting the coastline, and finally determining the evolution of coastlines. These conventional approaches usually cannot track with continuity the topographic changes of coastal environments and evaluate their consequent impacts on the environment and populations. Since the 1990s, the growing availability of radar satellites operating at microwave frequency bands has opened new possibilities to monitor the Earth's surface. In particular, the rapid development of synthetic aperture radar interferometry (InSAR) technology [24] has allowed for mapping the topography of the Earth on a global scale and generating digital elevation models (DEMs) of the terrain. InSAR technology relies on extracting the phase difference of couples of complex-valued SAR images of the terrain, acquired in different epochs and from slightly different orbital positions. In February 2000, the U.S. Shuttle Radar Topography Mission (SRTM) was launched and began acquiring data that, once adequately processed, has permitted the generation of a near-global DEM of the Earth [25], with a three-arc-second (and one-arc-second in some selected areas) resolution. More recently, in 2015, the TanDEM-X mission managed by DLR (Deutsches Zentrum für Luft-und Raumfahrt) [26] has yielded "updated" Earth DEMs. The comparison of InSAR-driven DEMs obtained from these different missions (SRTM and TanDEM-X), with a global scale coverage, allows for straightforward identification and study of the regions on Earth that have changed from 2000 to 2015. In particular, the DEMs comparison is useful to characterize the ground elevation of ocean-reclaimed lands. Although InSAR-driven DEMs have global coverage, their ground elevation accuracy is in the order of a few meters. Therefore, the comparison of the SRTM and TanDEM-X DEMs can only give a rough estimate of the occurred surface height changes. This is especially true for newly reclaimed lands located in low-elevation coastal zones (LECZ). On regional/continental scales, however, the results of such comparison could be sufficient to produce global measurements on the impact of land reclamation procedures on the coastal environment. Under climate change effects, potential 
flood risks in ocean-reclaimed regions are likely to increase including more frequent storm surges and sea-level increases [27]. Flood risks in coastal zones are well-studied [28-32], but the effects of potential inundations over new reclamation platforms have rarely been investigated. To this aim, InSAR technologies are particularly effective, permitting detailed investigations at a local scale. They can measure the Earth's surface topography with the generation of DEMs, and more importantly, can be used to investigate the ground surface changes with enhanced resolutions and accuracies using differential SAR interferometry (DInSAR) technique [33]. DInSAR is based on the generation and inversion of interferograms, representing phase differences between couples of complex-valued SAR images for the same area. Advanced multi-temporal DInSAR techniques [33-39] allow for the generation of a time-series of line-of-sight (LOS)-projected ground deformations. The use of DInSAR techniques is particularly valuable for analyzing ground subsidence in coastal regions $[40,41]$ and reclaimed lands [42,43]. In the latter case, because soft dredger fill used in reclamation projects takes a long time to consolidate [44], ground subsidence is inevitable, leading to a significant decrease in land elevation. Furthermore, coastal subsidence can trigger displacements of the seawall crest heights and increase the probability of wave overtopping in the case of an extreme weather event. The seawalls could also locally be subjected to degradations and instabilities, leading to significant displacements that are retrievable in the generated InSAR-driven ground displacement products. The measurement points correspond to a spatially dense grid of coherent objects on the ground. The obtained deformation time-series have an accuracy of a few millimeters, as demonstrated by crosscomparison analyses with ground-truth data $[45,46]$. With respect to other methods based on coarsely interpolating GPS/leveling data (only available in a few selected points over the coast) to the seawalls' location [47-49], DInSAR can monitor these infrastructure elements and the areas close to them and trace the changes that they are subjected to. Furthermore, two (or more) sets of SAR data collected from complementary illumination angles (e.g., from ascending and descending orbits) can also be processed by applying recently developed multi-track InSAR combination methods [50-53] that can allow for the generation of 2-D vertical (Up-Down) and lateral (East-West) ground (and related infrastructures) displacement time-series, circumventing the limitation of single-track InSAR methods that provide only the LOS-projected component of the ground deformation.

The main objective of our study was to demonstrate the capability of the InSAR technologies applied to the monitoring of ocean-reclaimed platforms at both regional/continental and local scales. First, at the regional/continental scale, we selected as test areas twelve Chinese cities with a population of more than five million and high-intensity coastal reclamation projects. We estimated the area extent and their elevation of the ocean-reclaimed new lands as retrievable by cross-comparing the InSAR-driven DEMs produced through the SRTM (in 2000) and the TanDEM-X (in 2015) missions. For the Yangtze River Delta (YRD) region, we derived coastline and land reclamation changes using traditional remote sensing interpretation methods (coastline-based methods). We then compared them to those assisted by InSAR-driven DEMs. In this manner, we intend to map the inundation areas of the selected Chinese cities and assess the flood risk increase in newly ocean-reclaimed lands. Second, we focused on the coastal area of Shanghai and studied the localized ground deformation signals affecting the ocean-reclaimed lands and its coastline. With respect to previous works on the same region $[45,46,54-56]$, the aim of this investigation was to analyze the impact of coastal subsidence and seawall deterioration in the case of a (potential) extreme flood event hitting the area. For this purpose, we split the Shanghai coastline into forty non-overlapping segments. Then, for every segment, we used the LISFLOOD-FP hydrodynamic model $[57,58]$ to calculate the extent of the inundated areas if the waves destroyed each segment individually. The wave overtopping probability and the size of damaged coherent structures in the inundated coastal region was estimated by considering a worst-case scenario. For the calculation of the wave overtopping, the extreme still water level (i.e., from Global Tide and Surge Reanalysis datasets) [59] was used, and was assumed to be chi-square distributed [60]. The coastal ground deformations were retrieved 
by applying a multi-temporal SBAS algorithm [36] to two independent sets of SAR data collected from March 2018 to July 2021 by the COSMO-SkyMed (X-band) and the Sentinel-1 (C-band) sensors over complementary (ascending/descending) orbits. Subsequently, the vertical (subsidence) ground deformation rate and the relevant time-series were obtained by applying the multi-track InSAR combination method proposed in Pepe et al. [51]. Combined ground deformation time-series were produced on a georeferenced spatial grid with a sampling of $80 \times 80 \mathrm{~m}$. The impact of a potential flood for every selected segment was evaluated by counting the number of high-coherent objects (e.g., the point scatterers (PSs)), as obtained by analyzing the stack of available COSMO-SkyMed data at the single-look scale, located within the georeferenced grid.

The results of our investigation will further demonstrate the effectiveness of InSAR methodologies for the study of the ocean-reclaimed lands. Specifically, for the Shanghai case, we show that the coastline segments located in the south, where the height of the seawall is lower, are especially at risk in the case of extreme flood events because they are characterized by higher wave overtopping probabilities and by a high density of coherent objects that a severe inundation could impact.

\section{Data and Methods}

\subsection{Study Area}

The coastal area of China comprises 14 provincial-level administrative regions between the latitudes of $18^{\circ} \mathrm{N}$ to $43^{\circ} \mathrm{N}$ and longitudes $104^{\circ} \mathrm{E}$ to $125^{\circ} \mathrm{E}$. These regions only account for $13 \%$ of China's total territorial area but contain $43.5 \%$ of the population [12]. Figures from the National Bureau of Statistics of China [61] show that the gross domestic product (GDP) of the coastal provinces was 41.6 trillion yuan (approx. USD 6.2 trillion) in 2015, 56\% of the total GDP of China. According to the China Marine Statistical Yearbook (2016) [62], along the $18,000 \mathrm{~km}$ of continental coastlines, there are 57 prefecture-level cities located along the $18,000 \mathrm{~km}$ coastline, with 23 cities having a population greater than five million (see Figure 1), which were, for our purposes, classified as large cities [63]. Among them, we selected twelve cities with high-intensity coastal reclamation projects as the primary subject of this paper that will be analyzed in detail.

Furthermore, we selected the Yangtze River Delta and the Shanghai region as case study areas. The YRD, an alluvial plain formed by sediment deposition from the Yangtze River [64], is one of the most crucial river delta regions of China and has the highest population density. In recent decades, intensive coastal reclamation has been conducted [7,64], yielding significant coastal changes. Shanghai is located in the Yangtze Estuary at the midpoint of the YRD and is one of the most densely populated and economically developed megacities globally. Most of Shanghai is at a low elevation (about 3-4 m above sea level) and has undergone high-intensity coastal reclamation (approx. $1192.5 \mathrm{~km}^{2}$ from 1960 to 2015 [65]) as well as constructing flood-control seawalls [66]. 


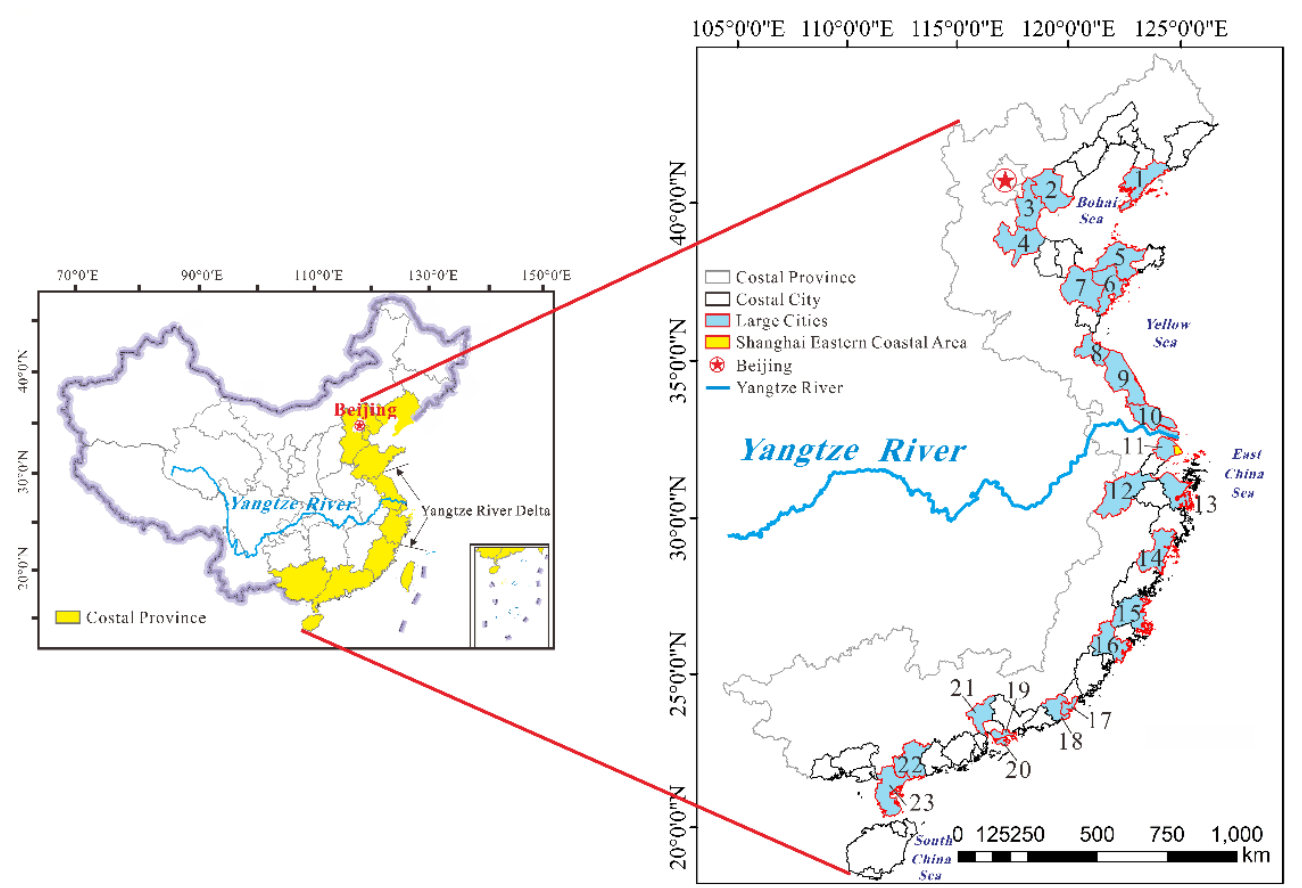

Figure 1. The left image shows the location of the coastal provinces of China and the Yangtze River Delta. The right image shows the location of the large cities on the coast of mainland China: (1) Dalian; (2) Tangshan; (3) Tianjin; (4) Cangzhou; (5) Yantai; (6) Qingdao; (7) Weifang; (8) Lianyungang; (9) Yancheng; (10) Nantong; (11) Shanghai; (12) Hangzhou; (13) Ningbo; (14) Wenzhou; (15) Fuzhou; (16) Quanzhou; (17) Shantou; (18) Jieyang; (19) Shenzhen; (20) Hong Kong; (21) Guangzhou; (22) Maoming; and (23) Zhanjiang.

\subsection{Digital Elevation Models (DEMs) and Satellite Images}

\subsubsection{Digital Elevation Models}

Open-source medium-resolution global digital elevation model (DEM) datasets [67] have widely been used to extract geomorphological features, especially in regional-scale studies. The U.S. Shuttle Radar Topography Mission has provided near-global DEM products since 2003 [25]. In our study, NASA's SRTM-1 V3 DEM product of one arc-second resolution (approx. $30 \mathrm{~m}$ at the equator) was utilized (https://earthexplorer.usgs.gov/ (accessed on 3 July 2021)). The Advanced Spaceborne Thermal Emission and Reflection Radiometer (ASTER) global DEM (Version 2) covers 99\% of the Earth's surface at one arcsecond resolution, which is also available from the USGS Earth Explorer site. The Advanced Land Observing Satellite (ALOS) has multiple instruments including the Panchromatic Remote-sensing Instrument for Stereo Mapping (PRISM), which is designed to map digital elevation. The ALOS WORLD 3D (AW3D) DEM includes $5 \mathrm{~m}$ and $30 \mathrm{~m}$ resolution; the former is distributed commercially, and the latter is freely available from the Japan Aerospace Exploration Agency (JAXA) website. Finally, a newly released (September 2018) global DEM, which has a three-arc-second resolution (TanDEM-X $90 \mathrm{~m}$; TDX90), has been developed by DLR (Deutsches Zentrum für Luft-und Raumfahrt) [26].

TDX90 DEM was derived from the standard TanDEM-X (TDX) DEM product that has a 0.4 arc second posting (approx. $12 \mathrm{~m}$ at the equator) and vertical accuracy of $2 \mathrm{~m}$ at a $90 \%$ confidence level [68]. TDX90 has a lower vertical accuracy than standard TDX, but is free of charge and more easily available. Globally, root mean square error (RMSE) of the elevation difference between the ground-based checkpoints and DEM extracted points for SRTM, ASTER, and AW3D30 DEMs were $6 \mathrm{~m} \mathrm{[69],} 8.68 \mathrm{~m}$ [70], and $4.4 \mathrm{~m}$ [71], respectively. However, for the TDX90 DEM, there is not an overall global assessment of its vertical accuracy. Hawker [72] found that compared with SRTM, ASTER, and AW3D30 DEMs, TDX90 has the best vertical accuracy in 32 low-slope floodplain sites. More details about each of these global DEMs are shown in Table 1. 
Table 1. SRTM, ASTER, AW3D30, and TanDEM-X 90 DEM.

\begin{tabular}{ccccc}
\hline $\begin{array}{c}\text { Open Global } \\
\text { DEM }\end{array}$ & $\begin{array}{c}\text { Acquisition } \\
\text { Time (Year) }\end{array}$ & $\begin{array}{c}\text { Spatial } \\
\text { Resolution (m) }\end{array}$ & Height Datum & $\begin{array}{c}\text { Vertical } \\
\text { Accuracy } \\
\text { (RMSE) }\end{array}$ \\
\hline SRTM & 2000 & 30 & EGM96 & $6 \mathrm{~m}$ \\
ASTER & $2000-2009$ & 30 & EGM96 & $8.68 \mathrm{~m}$ \\
AW3D30 & $2006-2011$ & 30 & EGM96 & $4.4 \mathrm{~m}$ \\
TDX90 & $2010-2015$ & 90 & WGS84 & $\mathrm{n} / \mathrm{a}$ \\
\hline
\end{tabular}

The vertical datum for TDX90 DEM is the World Geodetic System 1984 (WGS84) ellipsoid [68], whereas other DEMs are referenced vertically to the Earth Gravitational Model 1996 (EGM96) geoid [72]. Hence, pre-processing was conducted to convert the TDX90 DEM to the EGM96 height datum for data consistency. Figure 2 shows the final TDX90 DEM used in our study, with the location of major twelve coastal cities with highintensity land reclamation indicated by Figure $2 \mathrm{a}-1$.

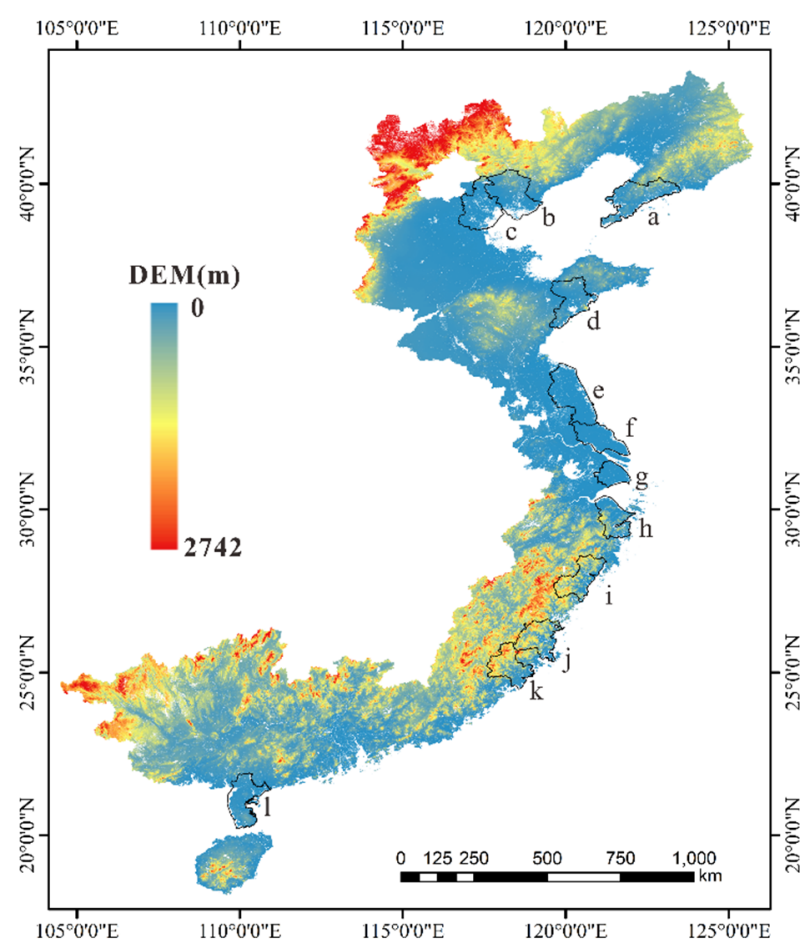

Figure 2. TDX90 DEM of the provinces on the coast of mainland China using the EGM96 height datum. The black polygons show the boundary of the significant cities considered in our study, labeled by letters: (a) Dalian; (b) Tangshan; (c) Tianjin; (d) Qingdao; (e) Yancheng; (f) Nantong; (g) Shanghai; (h) Ningbo; (i) Wenzhou; (j) Fuzhou; (k) Quanzhou; and (l) Zhanjiang.

\subsubsection{Landsat Images}

Landsat images acquired from 1983 to 2019 at 3-year intervals (78 total images) were selected to interpret the coastline of the YRD (Table 2). Six Landsat scenes with different paths / rows (Table 2) covered the entire YRD. The selected images had a criterion of zero or very little cloud coverage $(<1 \%)$ and zero pixels near the coastline blocked by clouds. We performed geometric corrections, radiometric calibrations, atmospheric corrections, and image mosaics to obtain a series of images covering the Yangtze Delta. The coastline in 2019 was vectorized first, and the changed regions of the coastline were modified to acquire the coastline in 2016, which was then used as a reference for the coastline in 2013. We iterated this method in discrete steps back to 1983. 
Table 2. List of Landsat images covering the coastal zone of the Yangtze River Delta.

\begin{tabular}{ccc}
\hline Year & Sensor Type & Path/Row \\
\hline 1983 & Landsat4 MSS $^{1}$ & $120 / 036,119 / 037,118 / 038$, \\
$1986,1989,1992,1995,1998$, & Landsat5 TM $^{2}$ & $118 / 039,118 / 040$, \\
$2001,2004,2007,2010$ & Landsat8 OLI $^{3}$ & $118 / 041$ \\
$2013,2016,2019$ &
\end{tabular}

${ }^{1}$ MSS is Multispectral Scanner, ${ }^{2}$ TM is Thematic Mapper, ${ }^{3}$ OLI is Operational Land Imager.

\subsubsection{Synthetic Aperture Radar Data}

The SAR datasets in this study include 78 CSK and 167 S-1A images. Images in the CSK dataset, acquired from 8 March 2018 to 20 June 2021 with descending passes, have a revisit time of 16 days. Images in the S-1A dataset, obtained from 18 March 2018 to 23 August 2021 with ascending passes, have a revisit time of 12 days. The CSK and S-1A data were acquired in the StripMap (SM) and interferometric wide-swath (IW) modes, respectively.

\subsection{Methodology}

This section briefly introduces the main techniques and the methodologies applied to analyze the flood risk over the selected ocean-reclaimed lands.

\subsubsection{Interferometric Synthetic Aperture Radar Techniques}

Interferometric synthetic aperture radar (InSAR) techniques $[24,73]$ rely on the extraction and analysis of the phase difference between couples of complex-valued SAR images collected over the same area on Earth and from slightly different orbital positions. They have been applied to generate elevation maps of the Earth's surface and produce DEMs of the terrain [74,75] (see Section 2.2.1). The differential SAR interferometry technology $[24,76,77]$ is an evolution of InSAR, which was developed to obtain maps of the radar line-of-sight-projected ground displacements. Historically applied to analyze single deformation episodes such as the ground ruptures due to large earthquakes [78,79], DInSAR has then evolved to produce ground deformation time-series using multi-temporal InSAR methods $[34,38,80,81]$. Among these methods, a crucial role has been played by the SBAS technique [36]. It processes a group of short baseline interferograms characterized by low phase decorrelation effects [82]. Well-processed SAR pixels characterized by temporal coherence values [83] higher than a given threshold (in our work, this threshold value was 0.5$)$ were identified and used for the subsequent analyses. To increase the density of well-processed coherent SAR pixels, we also applied a region-growing strategy [84]. SAR images collected from ascending and descending passes allow one to discriminate from the LOS-projected ground deformation time-series the vertical (subsidence) ground deformations from the lateral East-West movements by applying multi-track satellite combination methods such as the minimum acceleration (MinA) combination technique [51]. The ground deformation measurement accuracy in single interferograms depends on the used operational wavelength $\lambda$. If $\Delta \phi_{1,2}$ is the (unwrapped) phase difference between the SAR images collected at times $t_{1}$ and $t_{2}$, the standard deviation $\sigma_{d e f}$ of the ground displacement occurring between the observed epochs is equal to $\sigma_{d e f}=\lambda \sigma_{\Delta \phi_{1,2}} / 4 \pi$ where $\sigma_{\Delta \phi_{1,2}}$ is the standard deviation of the unwrapped phases that depends on both the decorrelation noise and the phase unwrapping errors [82]. With X-band COSMO-SkyMed and Sentinel-1 data, the operational wavelength is about $3.1 \mathrm{~cm}$ and $5.4 \mathrm{~cm}$. Accordingly, the measurement accuracy is on the order of a few millimeters, depending on the amount of decorrelation noise and phase unwrapping artifacts present. Quantitative analyses [54,85-87], based on the comparison of SBAS-driven results with GPS/leveling data, have shown that the accuracy of the SBAS-based LOS-projected ground displacement and mean deformation rate is to the order of 3-5 mm and $1 \mathrm{~mm} /$ year, respectively. The accuracy of the 2-D (Up/Down and East-West) components of the ground deformations, as obtained by combining SAR data acquired from ascending and descending orbits of a sensor with approximately the same side illumination angle, can roughly be derived as a function of the accuracy of LOS- 
projected products $\sigma_{L O S}$ by $\sigma_{U p-D o w n}=2 \sigma_{L O S} / \cos \vartheta$ and $\sigma_{E a s t-W e s t}=2 \sigma_{L O S} / \sin \vartheta$ where $\vartheta$ is the sensor-to-target wave (local) incidence angle. Accordingly, Up/Down ground deformation products are more accurate than East-West products, whereas there is minimal sensitivity to ground movements along the North-South direction. Interested readers can find details on the SBAS and MinA techniques and additional information on the ground deformation measurements accuracy by Casu et al. and Pepe et al. [86,88].

\subsubsection{Coastal Reclamation Area Detection Method}

Coastal reclaimed lands were retrieved on the regional/continental scale by comparing the elevation height recorded in the oldest SRTM with the newest TDX90 global DEM (see Table 1). The land-sea border can be validated, since it is easy to distinguish between the land and sea areas of different elevations. We conducted superposition analyses of DEMs to detect coastal reclamation areas, called the DEM-based method. The specific steps performed were (i) produce the vector boundaries of SRTM and TDX90 DEM, denoted by $\mathrm{B}_{\mathrm{S}}$ and $\mathrm{B}_{\mathrm{T}}$; (ii) subtract $\mathrm{B}_{\mathrm{S}}$ from $\mathrm{B}_{\mathrm{T}}$ and obtain the vector boundary of reclamation land, denoted by $\mathrm{B}_{\mathrm{C}}$; (iii) using vector $\mathrm{B}_{\mathrm{C}}$ as a mask, clip the TDX90 DEM within it, and obtain the DEM of the newly-formed land, denoted by DEM $\mathrm{C}_{\mathrm{C}}$; and (iv) clip the $\mathrm{DEM}_{\mathrm{C}}$ with the administrative boundary of coastal cities, and obtain the DEM for each prefecture-level city.

\subsubsection{Quantitative Analysis Method of Coastline Change}

We used the coastline interpretation method discussed in Section 2.2.2 to vectorize thirteen coastlines in different years of the YRD. We then employed the Digital Shoreline Analysis System (DSAS, version 5.0) [89] to compute and quantitatively analyze the rate of coastline changes. The coastline in 1983 was used as a baseline, and a series of transects perpendicular to the baseline were generated along the shoreline with equal spacing of $500 \mathrm{~m}$. Note that the selected Chinese coastal regions have a smooth topography; hence, the considered spatial spacing is adequate to perform the analyses at the regional/continental scale. In the analysis of land area change, only the oldest (in 1983) and newest (in 2019) coastlines were considered, and the region between them was regarded as a land accretion/erosion area. We here define this coastline change analysis method the coastline-based method.

\subsubsection{Coastline Segmentation and Coastal Flood Modeling}

Under the combined effect of wave, subsidence, and the flood-control seawalls (with different heights), certain segments of seawalls are more vulnerable to burst or more likely to be overtopped by seawater. However, there is a low probability that all the vulnerable seawalls would simultaneously lose efficacy. The possibility of a single seawall segment failing is more realistic. Thus, we divided the seawall system of Shanghai into 40 segments, with the length of every section being about $2 \mathrm{~km}$. We assumed that each section could fail individually, so there were 40 independent scenarios. For the flood modeling, we utilized the two-dimensional hydrodynamic model LISFLOOD-FP, a rasterbased flood inundation model, to simulate the extent and depth of inundation of the coastal floodplain $[57,90]$. LISFLOOD-FP has been widely used to simulate the evolution of coastal flooding and performed well in many coastal inundation studies [91-94]. We used the model's Acceleration Solver, which employs simplified shallow water equations by neglecting the convective acceleration term [58]. Three files need to be prepared to run the model. One is the elevation file (raster DEM). The second is a file with the information of boundary condition types used to simulate the initial state of flood along the coast. It contains coordinates of water points, water depth, and the form of water flow. Here, the fixed free surface elevation was selected, assuming seawater always maintains a specific water depth during inland flooding. The third is a parameter file, which states the solver, sets the storage path and name, etc. We used the Global Tide and Surge Reanalysis (GTSR) datasets [59] as the water depth. It simulates extreme sea levels with a 100-year return period and takes the effects of tides and surges into account. The sea levels in GTSR have been corrected to the same datum as SRTM (i.e., EGM96) [95]. 


\subsubsection{Flood Risk Maps Evaluation}

Here, we describe the strategy adopted to generate risk maps in coastal areas due to potential extreme weather flood events. We considered the presence of a network of seawalls along the coastline, and we applied the LISFLOOD-FP hydrodynamic model to estimate the extent of the regions inundated after a flood event. The model describes the dynamic propagation of waves on floodplains using continuity and momentum equations, discretized over a grid mesh $[96,97]$. During dynamic simulations, the wave propagation was controlled by friction (Manning's number) and gravity forces [94,98]. The computation of a risk map requires the knowledge of the probability that a hazard could occur and the evaluation of the impact of a disaster event on the population when it happens. To this aim, we studied the characteristics of the seawall networks, with a specific focus on those deployed along the Shanghai coastline. We remark that the design standard for seawall heights is based on the combination of extreme wave heights and extreme still sea levels. This standard is not universal for different coastal cities in China because of their various economies and natural environments [99]. Due to Shanghai's important place in the national economy, the protection standard of the seawalls in Shanghai is relatively high, and about $78 \%$ of these projects are at a standard that can withstand a 100-year storm tide plus waves caused by force-12 winds [100]. The dataset, which contains the crest heights of seawalls in 2010 along coastal Shanghai, shows that the minimal seawall height is around $7.6 \mathrm{~m}$. The GTSR datasets show that the still extreme sea level of Shanghai is about $3.71 \mathrm{~m}$ and is much lower than the minimal seawall height. Thus, there is a small probability of overtopping. To estimate this probability, we considered that the extreme sea level is not a constant number and could be perturbed higher or lower under the influence of climatic factors (e.g., wind speed). Specifically, to calculate the probability of overtopping, we considered that the extreme still water level (i.e., from GTSR datasets) had a Pearson Type III distribution $[99,101]$ that under proper conditions may be approximated with a chi-square distribution of an average known value. It is also worth remarking that another commonly used distribution for extreme water levels in hydraulics is also the generalized extreme value distribution [102-104].

The probability chi-square density function (PDF) is:

$$
f(x)=\frac{1}{2^{\frac{k}{2}} \Gamma\left(\frac{k}{2}\right)} x^{\frac{k}{2}-1} e^{-\frac{x}{2}}
$$

where $k$ (integer number) is the degree of freedom; $x$ is the water level; and $\Gamma$ is the gamma function. The expectation value of the chi-distribution equals $k$, which in the case of the Shanghai area is equal to 3.71 and has been rounded to 4 .

Once the PDF is determined, the probability of overtopping can be calculated as:

$$
\operatorname{Pr}(\text { Water-level } \geq \text { Seawall-height })=1-\operatorname{Pr}(\text { Water-level }<\text { Seawall-height })
$$

To obtain some simple predictions on future risk conditions due to extreme flood events, we also corrected the seawall height for ten years from now, considering, as a worst-case, that the observed subsidence rate of the seawalls will remain constant. Previous works have demonstrated that the subsidence of ocean-reclaimed lands is not linear but has a time-decay behavior [105]. Nonetheless, for the scope of the present investigation, we focused exclusively on the ground (subsidence) deformation rate to identify the critical sectors of the Shanghai coast to provide some simple predictions on future evolution and impacts of extreme floods on the Shanghai coastal urban texture.

Accordingly, for pixels located in correspondence with the seawall location, in Equation (2), we used the corrected (possible) future height given by:

$$
H_{t 2}=H_{t 1}+V\left(t_{2}-t_{1}\right)
$$


where $t_{1}$ is the time when seawall leveling was measured and $t_{2}$ is a time in the future. $V$ is the Up-Down mean velocity obtained from CSK/S-1A datasets, which is a negative value when subsidence occurs. $H_{t 1}$ is the seawall height at $t_{1}$, and $H_{t 2}$ is the corrected seawall height at $t_{2}$. For each segment of the seawalls, we also evaluated the impact of a potential flood by counting the number of high-coherent point scatterers (PSs) that fall within the flooded regions. The PSs points reflect, at most, the distribution of man-made structures such as buildings, roads, seawalls, and ports. We analyzed a set of CSK differential SAR interferograms computed at the single-look (full) spatial resolution. We applied an azimuth split-spectrum algorithm that allows for straightforward identification of those scatterers that preserve their coherence at different non-overlapped frequency bands. This method consists of splitting the azimuth spectra of couples of SAR images into two non-overlapping slices (the upper and lower Doppler bands) from which two distinctive interferograms (from the upper and lower bands) can be generated. The phase difference of the upper and lower interferograms leads to a figure on the phase stability of the scatterers. It permits the identification of objects that are coherent at both low and up frequencies. Specifically, the following coherence-like estimator:

$$
\Gamma=\frac{\left|\sum_{k=0}^{M-1} \exp \left[j\left(\phi_{\text {high }}-\phi_{\text {low }}\right)\right]\right|}{M}
$$

is calculated, where $j=\sqrt{-1}$, and $\phi_{\text {high }}, \phi_{\text {low }}$ are the relevant $k$-th DInSAR interferograms that consider the high and the low azimuthal (Doppler) frequencies, respectively. The detected high-coherent points (i.e., those related to PS objects) are identified by simply considering those pixels with a coherence higher than a given threshold, which in our case is equal to 0.35 . The map of PS pixels can then be geo-referenced for the subsequent analyses. Details of the adopted azimuth split-spectrum method can be found in Falabella et al. [106].

Thus, the density of detected high-coherent points (denoted by $D_{P}$ ) in the inundation areas are used as an indication of the flood impacts on the coastal communities:

$$
D_{P}=\mathrm{Num}_{1} / \mathrm{Num}_{2}
$$

where $N u m_{1}$ is the number of high-coherent points in the given cell of the geocoded spatial grid, and $\mathrm{Num}_{2}$ is the extent of every patch of the $90 \times 90 \mathrm{~m}$ geocoded grid used to implement the risk flood analyses in coastal regions.

\section{Experimental Results}

\subsection{Landforms in Coastal Reclamation Areas of Twelve Large Coastal Cities of China}

The SRTM DEM gives the location and elevation of land in 2000, and the TDX90 DEM provides the same information for 2015. Comparing both DEMs, we can estimate the coastal reclamation areas from 2000 to 2015. According to the area and shape of reclamation land (Figures 3 and 4), these twelve cities can be categorized into four types: (i) Cities that have expanded their coastlines significantly with a straight outline including Tangshan (b) and Tianjin (c), which have built a port and a harbor, respectively; (ii) Cities that have had relatively uniform reclamation projects including Dalian (a), Yancheng (e), and Nantong (f). In these three cities, many marine aquaculture ponds have been built in the reclaimed regions; (iii) Economically developed cities, with large reclamation areas and straight artificial seawalls built on the periphery including Shanghai (g) and Ningbo (h); and (iv) Cities where coastal reclamation projects have been small and intermittent including Zhanjiang (1), Qingdao (d), Wenzhou (i), Fuzhou (j), and Quanzhou (k). 


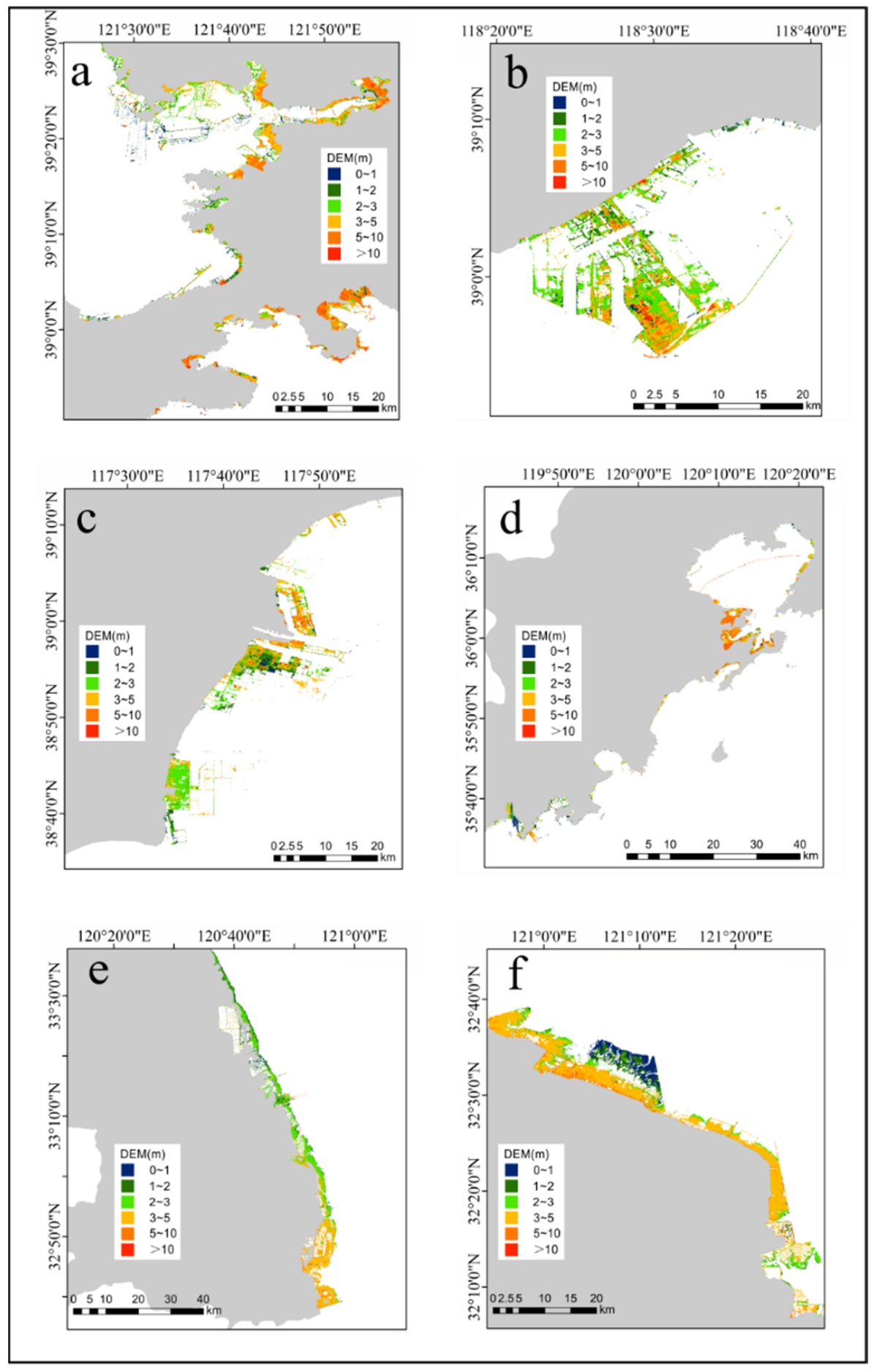

Figure 3. Hypsometry of newly reclaimed land in (a) Dalian; (b) Tangshan; (c) Tianjin; (d) Qingdao; (e) Yancheng; and (f) Nantong. 


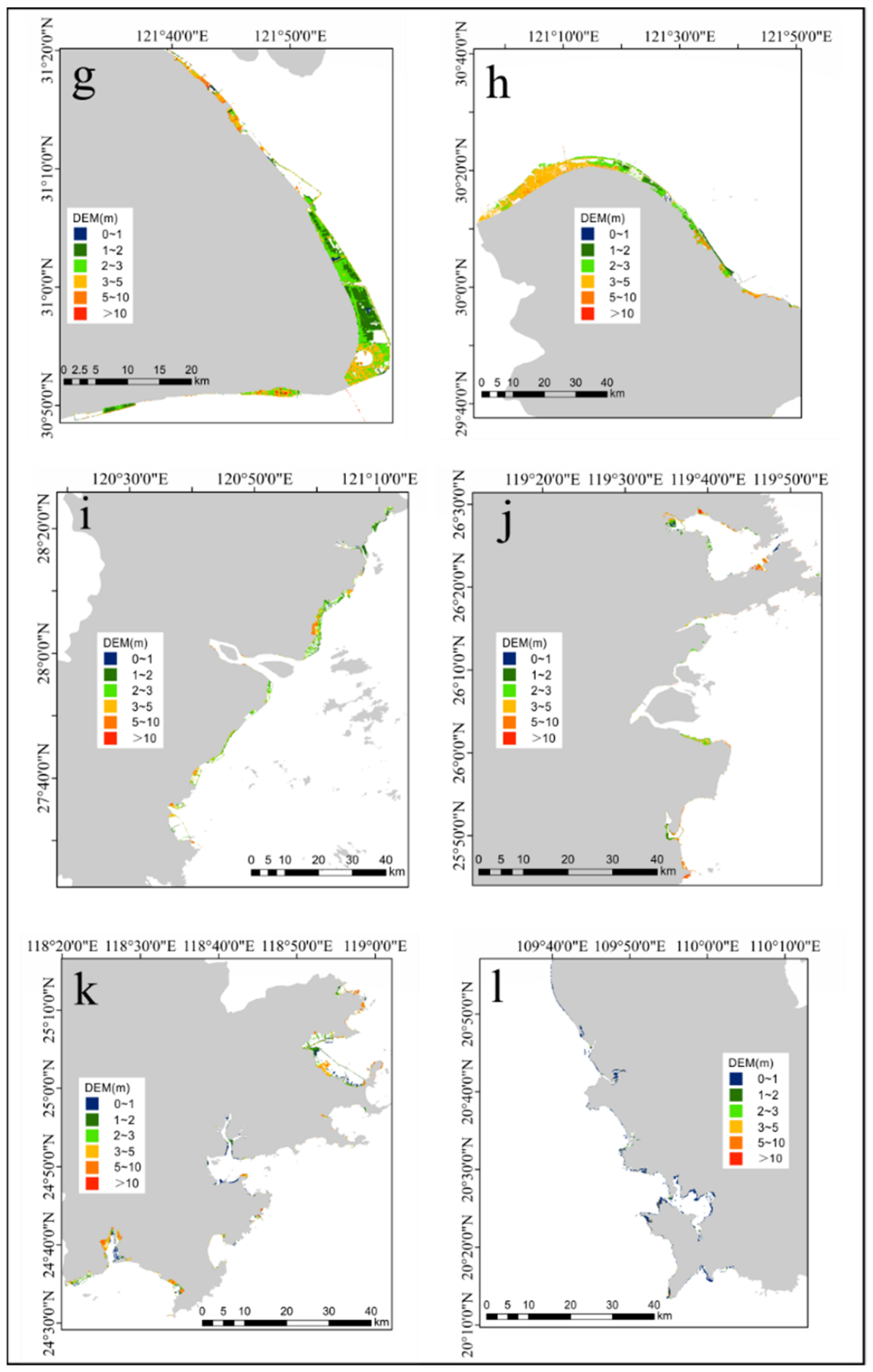

Figure 4. Hypsometry of newly reclaimed land in (g) Shanghai; (h) Ningbo; (i) Wenzhou; (j) Fuzhou; (k) Quanzhou; and (1) Zhanjiang.

From 2000 to 2015, the total reclamation area of the twelve large coastal cities considered here was $3167.60 \mathrm{~km}^{2}$ (Table 3), accounting for $2.34 \%$ of the entire administrative area. Specifically, the coastal reclamation area of the cities in the Bohai Bay $(\mathrm{a}-\mathrm{c})$, the cities in the YRD (e-h), and the cities in southern China (i-l) were $1290.28 \mathrm{~km}^{2}, 1375.97 \mathrm{~km}^{2}$, and $409.25 \mathrm{~km}^{2}$, respectively. This means their proportions in the total reclamation area were $40.73 \%, 43.44 \%$, and $12.92 \%$, respectively. The cities of the YRD had the largest reclamation area, the largest inundation area of the whole city $\left(11,608.18 \mathrm{~km}^{2}, 69.19 \%\right)$, and the largest reclaimed land $\left(1136.94 \mathrm{~km}^{2}, 59.97 \%\right)$. For the proportion of the reclamation area in the city, 
the maximum and minimum were $4.96 \%$ (h: Ningbo) and 0.62\% (1: Zhanjiang). Although the administrative areas of the different cities are diverse, there was a positive correlation between reclamation areas and their proportions in the administrative regions (correlation coefficient was 0.91). The average elevations in the newly reclaimed land ranged from $1.47 \mathrm{~m}$ (1: Zhanjiang) to $7.15 \mathrm{~m}$ (j: Fuzhou), and as shown in Figures 3 and 4, there was almost no grid with an elevation of more than $10 \mathrm{~m}$. Thus, the large majority of newly reclaimed land considered here was less than $10 \mathrm{~m}$ and belonged to the LECZ [107].

Table 3. Important statistics for coastal cities of China that have experienced significant land reclamation including population, reclamation area, average elevation, and projected inundation areas in total city area and reclaimed land. The last column shows the proportion of flood areas in reclaimed land to total flooded areas of each city.

\begin{tabular}{|c|c|c|c|c|c|c|}
\hline $\begin{array}{l}\text { Coastal } \\
\text { Megacity }\end{array}$ & $\begin{array}{l}\text { The } \\
\text { Population at } \\
\text { the End of } 2015 \\
\text { (Thousand) }\end{array}$ & $\begin{array}{c}\text { Reclamation } \\
\text { Areas }\left(\mathbf{k m}^{2}\right) \\
\text { and Percentage } \\
\text { in the City }\end{array}$ & $\begin{array}{c}\text { Average } \\
\text { Elevation (m) } \\
\text { in the } \\
\text { Reclaimed } \\
\text { Land }\end{array}$ & $\begin{array}{c}\text { Flood Zone } \\
\left(\mathrm{km}^{2}\right) \text { and } \\
\text { Percentage of } \\
\text { the Total City } \\
\text { Area }\end{array}$ & $\begin{array}{c}\text { Flood Zone } \\
\left(\mathrm{km}^{2}\right) \text { and } \\
\text { Percentage of } \\
\text { the Reclaimed } \\
\text { Area }\end{array}$ & $\begin{array}{c}\text { The Ratio of } \\
\text { Reclaimed Area } \\
\text { Flood Zones to } \\
\text { Total City Flood } \\
\text { Zones }\end{array}$ \\
\hline (a) Dalian & 6987 & $634.38(4.95 \%)$ & 4.35 & $188.93(1.48 \%)$ & 173.48 (27.35\%) & $91.83 \%$ \\
\hline (h) Ningbo & 7825 & $451.13(4.96 \%)$ & 2.78 & $927.65(10.20 \%)$ & $333.13(73.84 \%)$ & $35.91 \%$ \\
\hline (b) Tangshan & 7801 & $409.65(3.00 \%)$ & 2.87 & $\begin{array}{c}1561.72 \\
(11.43 \%)\end{array}$ & $140.90(34.40 \%)$ & $9.02 \%$ \\
\hline (e) Yancheng & 7230 & $407.93(2.59 \%)$ & 2.89 & $\begin{array}{c}8650.09 \\
(55.01 \%)\end{array}$ & 363.75 (89.17\%) & $4.21 \%$ \\
\hline (f) Nantong & 7300 & $374.21(4.11 \%)$ & 3.20 & $\begin{array}{c}1740.87 \\
(19.13 \%)\end{array}$ & 325.25 (86.92\%) & $18.68 \%$ \\
\hline (c) Tianjin & 15,470 & $246.25(2.06 \%)$ & 4.63 & $\begin{array}{c}1517.93 \\
(12.72 \%)\end{array}$ & 142.45 (57.85\%) & $9.38 \%$ \\
\hline (g) Shanghai & 24,153 & $142.70(2.65 \%)$ & 2.76 & $289.57(5.37 \%)$ & $114.81(80.45 \%)$ & $39.65 \%$ \\
\hline (i) Wenzhou & 9117 & $135.22(1.19 \%)$ & 3.41 & $734.43(6.47 \%)$ & $118.62(87.72 \%)$ & $16.15 \%$ \\
\hline (k) Quanzhou & 8510 & $103.61(0.94 \%)$ & 3.48 & $142.07(1.28 \%)$ & $70.64(68.18 \%)$ & $49.72 \%$ \\
\hline (j) Fuzhou & 7490 & $92.50(0.82 \%)$ & 7.15 & $278.18(2.46 \%)$ & $43.98(47.55 \%)$ & $15.81 \%$ \\
\hline (d) Qingdao & 9097 & $92.10(0.84 \%)$ & 4.44 & $115.42(1.05 \%)$ & $24.82(26.95 \%)$ & $21.50 \%$ \\
\hline (l) Zhanjiang & 7241 & $77.92(0.62 \%)$ & 1.47 & $629.83(4.98 \%)$ & $43.99(56.46 \%)$ & $6.99 \%$ \\
\hline Total & 118,221 & $3167.60(2.34 \%)$ & & $\begin{array}{l}16,776.69 \\
(12.42 \%)\end{array}$ & $\begin{array}{c}1895.82 \\
(59.85 \%)\end{array}$ & $11.30 \%$ \\
\hline
\end{tabular}

\subsection{Inundation Mapping of Twelve Coastal Cities}

Overall, $12.42 \%$ of the total land in all cities considered will be flooded under extreme sea level, and this impact will be more intense in newly reclaimed land, of which 59.85\% $\left(1895.82 \mathrm{~km}^{2}\right)$ will be flooded Table 3. In particular, the inundation proportion of reclaimed land was highest in Yancheng (89.17\%), followed by Wenzhou (87.72\%), Nantong (86.92\%), and Shanghai $(80.45 \%)$. Yancheng borders Nantong to the south. The average elevation of these two cities is low (2.74 $\mathrm{m}$ and $4.05 \mathrm{~m}$, respectively); in these locations, as shown in Table 3 and Figure 5 the inundation proportion of the entire city area is also very high (55.01\% and 19.13\%, respectively). In addition, Yancheng-Nantong includes a large area of aquaculture ponds and silty-sandy beach within reclaimed lands, and there are extensive deep-water ( $>4 \mathrm{~m}$ ) flooded areas (Figure 6e,f). Conversely, for Shanghai and Wenzhou, the inundation proportion of the entire city is only about $6 \%$, far less than reclaimed regions (approx. 85\%). Table 3 and Figure 5 show that Ningbo and Quanzhou have a similar inundation proportion for reclaimed regions (approx. 70\%). Ningbo's floodplain is concentrated in the north (Figure $7 \mathrm{~h})$, and its total inundation area $\left(333.13 \mathrm{~km}^{2}\right)$ ranked second in our list. However, Quanzhou's inundation area $\left(70.64 \mathrm{~km}^{2}\right)$ is relatively small. For Tangshan-Tianjin, most coastal wharves will be submerged (Figure $6 \mathrm{~b}, \mathrm{c}$ ), and about $12 \%$ of the total city area will be flooded. As shown in Table 3, for Dalian and Qingdao, flood areas, flood percentage of the whole city area, and flood percentage of the reclaimed area were relatively low due to high average elevations (81.9 $\mathrm{m}$ and $55.1 \mathrm{~m}$, respectively). 
The last column in Table 3 shows the effects of elevation changes in newly reclaimed land on flood inundation. Based on this index, we categorized these cities into four groups. For Dalain, $>90 \%$ of the flood inundation occurred in newly reclaimed lands; followed by Quanzhou, Shanghai, and Ningbo ( $>35 \%$ and $<50 \%$ ); then, Qingdao, Nantong, Wenzhou, Fuzhou ( $>15 \%$ and $<25 \%)$; and Tianjin, Tangshan, Zhanjiang, and Yancheng, where $<10 \%$ of the flood inundation occurred in the newly reclaimed land.

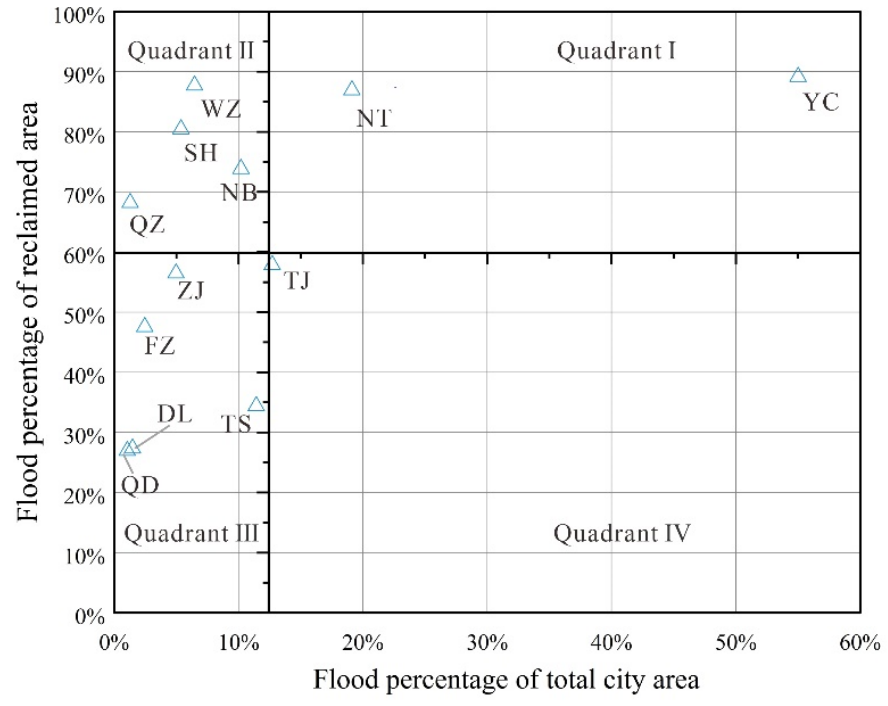

Figure 5. Phase diagram of flood percentage assessment results, showing the relative severity of flood disaster in two dimensions (i.e., flood percentage of total city area in the horizontal axes and flood percentage of reclaimed area in the vertical axes). Coordinates $(12.42 \%, 59.85 \%)$ represent the overall situation, described in the last row of Table 3. City names are displayed in the abbreviated format: Nantong is NT, Yancheng is YC, Wenzhou is WZ, Shanghai is SH, Ningbo is NB, Quanzhou is QZ, Zhanjiang is ZJ, Fuzhou is FZ, Dalian is DL, Qingdao is QD, Tangshan is TS, and Tianjin is TJ.

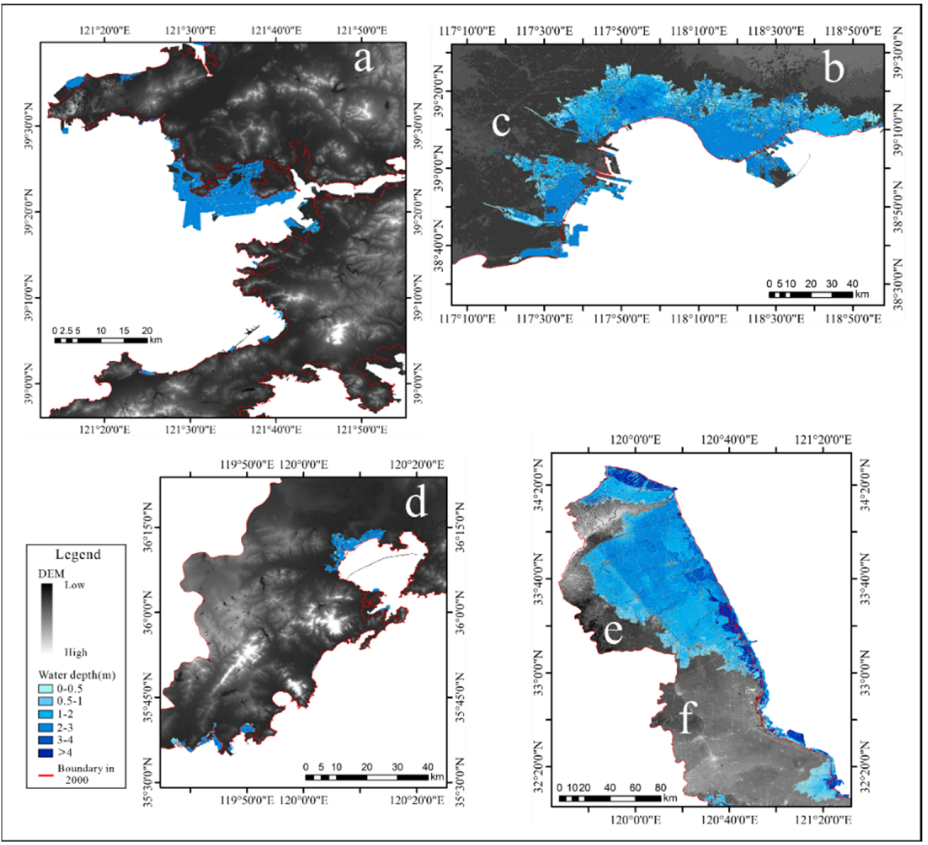

Figure 6. Inundation map under a 100-year return period flood for: (a) Dalian; (b,c) Tangshan-Tianjin; (d) Qingdao; (e,f) Yancheng-Nantong. 


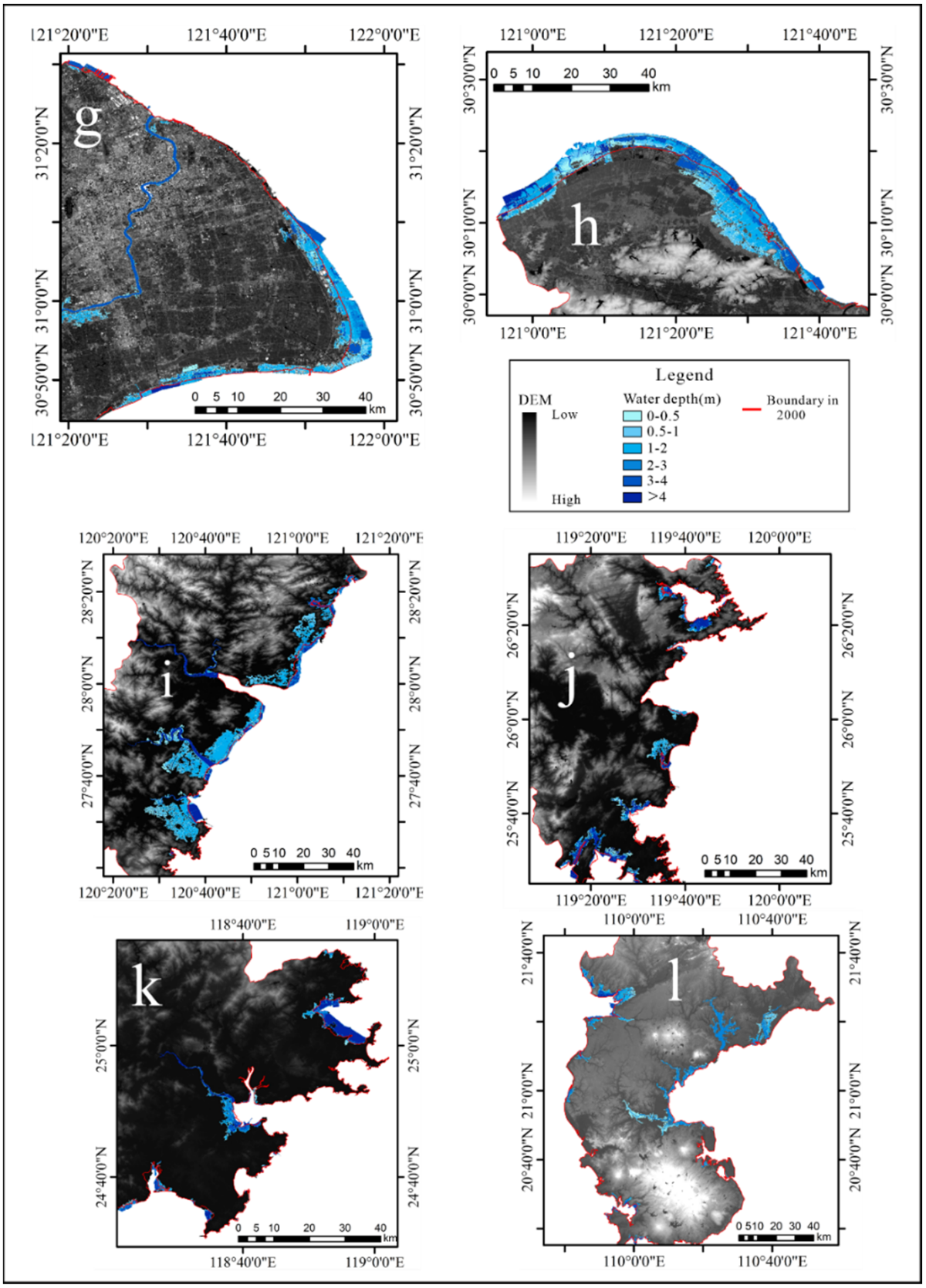

Figure 7. Inundation map under a 100-year return period flood for (g) Shanghai; (h) Ningbo; (i) Wenzhou; (j) Fuzhou; (k) Quanzhou; and (1) Zhanjiang.

\subsection{Coastal Evolution in the Yangtze River Delta}

We compared the coastlines of the YRD in 1983 and 2019 using Landsat images as described above (Table 2) to obtain the land expansion/erosion over the past 36 years. We divided the Yangtze River Delta into six segments from north to south (Figure 8) and quantitatively analyzed them for temporal and spatial change rates. Overall, most segments in the Yangtze Delta showed a seaward expansion (i.e., accretion). The average rate of shoreline expansion was $60 \mathrm{~m} / \mathrm{yr}$. Only a small section within segment one from the Guanhe River Estuary to Biandan Port in northern Jiangsu Province (labelled by (a) in Figure 8) and a section in southern Shanghai within segment 3 (labelled by (b) in Figure 8) experienced slight erosion (marked by red in Figure 8). The rate of coastline expansion in segment 2 (covering Yancheng and Nantong) and segment 4 (surrounding Ningbo) is much greater than in other locations. The time-series analysis shows that the rates of these two segments fluctuate considerably, and the change rate was most significant from 2001 to 
2016, which indicates that most reclamation projects for these cities occurred during this time. This is consistent with the results in Figures 3 and 4. Segment 3 covers the mainland of Shanghai, and segment 6 covers three islands in the Yangtze Estuary (Chongming, Hengsha, and Changxing Island) under Shanghai's administration. Segments 3 and 6 jointly express the total reclamation situation of Shanghai. The overall expansion speed of Shanghai's shoreline was between $29.4 \pm 7.5$ and $44.8 \pm 10.5 \mathrm{~m} / \mathrm{yr}$, with the expansion rate of the islands being larger than the mainland. Segment 1 is in the northernmost region of the Yangtze River Delta and has the smallest shoreline expansion rate. City-wise, Ningbo (segment 4) had the highest-intensity reclamation, followed by Yancheng and Nantong (segment 2), while Shanghai (segments 3 and 6) was relatively low.



Figure 8. Area variation and rate of coastline change in the Yangtze Delta. The delta's shoreline was divided into six segments based on coastline change rates and geographical characteristics. The separation of segments 1 and 2 was due to the reclamation intensity. Segment 2 to segment 5 were divided by the Yangtze Estuary, the Qiantang River Estuary, and the Yongjiang River Estuary from north to south. Segment 6 consists of three islands administered by Shanghai. Sections $(\mathbf{a}, \mathbf{b})$ indicate locations where shoreline erosion has occurred.

\subsection{Flood Risk Mapping of Shanghai}

Figure 4 and Table 3 show that four southern cities (Wenzhou, Fuzhou, Quanzhou, and Zhanjiang) and Qingdao have carried out low-intensity and spatially intermittent reclamation projects. The coastal reclamation activities in Dalian, Yancheng, and Nantong were mainly for aquaculture, salt pan, and cultivation [2]. For Tangshan and Tianjin, the sea enclosure was primarily for constructing new ports and harbors. Both Shanghai and 
Ningbo have utilized a large reclamation land area for human habitation. Especially in Shanghai, a township with a population of 830,000 named Lingang New City was built here. Shanghai is unique for its continuous artificial seawalls, low-elevation topography, and large population. Additionally, subsidence has been widely confirmed in the reclamation area of Shanghai $[45,46,108]$ from multi-platform InSAR measurements. In this work, we also show DInSAR-driven ground displacement maps that are useful for insights into the future evolution of coastline subsidence. The analyses presented here have been carried out at multi-look scales using different sets of SAR images, as detailed in the following Section 3.4.1.

\subsubsection{Analysis of High-Coherent Objects in the Shanghai Coastal Area}

Using the SBAS approach, we obtained separate deformation time series of two platforms in the same periods. For both, the LOS-projected deformation time series were calibrated to a common reference pixel (identified by the red star in Figure 9), whose deformation was nearly zero. Then, the LOS-projected deformation measurements were preliminarily geocoded to a reference (oversampled) latitude/longitude grid with a grid size of about $3 \times 3 \mathrm{~m}$. Finally, on the common geocoded area between the CSK and S-1A SAR data footprints, we applied the MinA combination approach [51] to decompose the LOS deformation time series into Up-Down and East-West directions. The mean deformation velocity map in the Up-Down direction is shown in Figure 9c. We can conclude that the Up-Down subsidence mainly occurred in the eastern region, especially in the triangular area near Pudong Airport. The areas that were subjected more to subsidence were the object of our subsequent investigations. We focused on the coastline sectors characterized by significant ground subsidence rates, and analyzed the deformations associated with the seawall instabilities.

To estimate the impact of a potential flood on the coastal regions, we also analyzed high-resolution CSK images using the azimuth split-spectrum method [106] and the strategy outlined in Section 2. The spatial distribution of the high-coherent objects in the investigated area is shown in Figure 10a.

As shown in Figure 10a, along the coast, high-coherent objects are significantly concentrated in the south-central part of Shanghai, reflected by high-density grids. In the southwest of Dishui Lake and the east-central part of Shanghai, the density of highcoherent objects is intermediate. In contrast, other regions have relatively low densities of coherent targets.

\subsubsection{The Inundation Map for Different Segmentation Scenarios}

Following Section 2, we split the coastline seawalls into forty non-overlapping segments and estimated the probability of wave overtopping and flood impacts in the case of an extreme weather event under the failure of each individual segment by considering the relevant seawall height and Equations (1) and (2). The impact is calculated by applying the LISFLOOD-FP hydrodynamic model [57,58], assuming that, for every selected sector, incoming waves overpass the barriers and the seawall sector has a severe failure. The worst-case where the seawall is destroyed was also considered in the simulations. The combined CSK/S-1 2018-2021 mean Up-Down ground deformation rates (see Figure 9) were also used to obtain rough estimates of the seawall height corrections due to subsidence for ten years from now (i.e., in 2030). However, the observed ground deformation (subsidence) rates along the Shanghai coastline from 2018 to 2021, which agreed with what was expected from previous work [105], were to the order of a few centimeters per year. Accordingly, the applied seawall height corrections did not significantly affect the estimates of the wave overtopping probabilities (see Equation (3)), and only marginally changed projections for the areas where the subsidence rate was higher (Figure 9). Overall, the probability of wave overtopping remains very low in the northern sectors and more significant in the southern coastal sectors where the seawalls are lower. The simulation results that considered the failure of each segment are shown in Figures 11 and 12. 

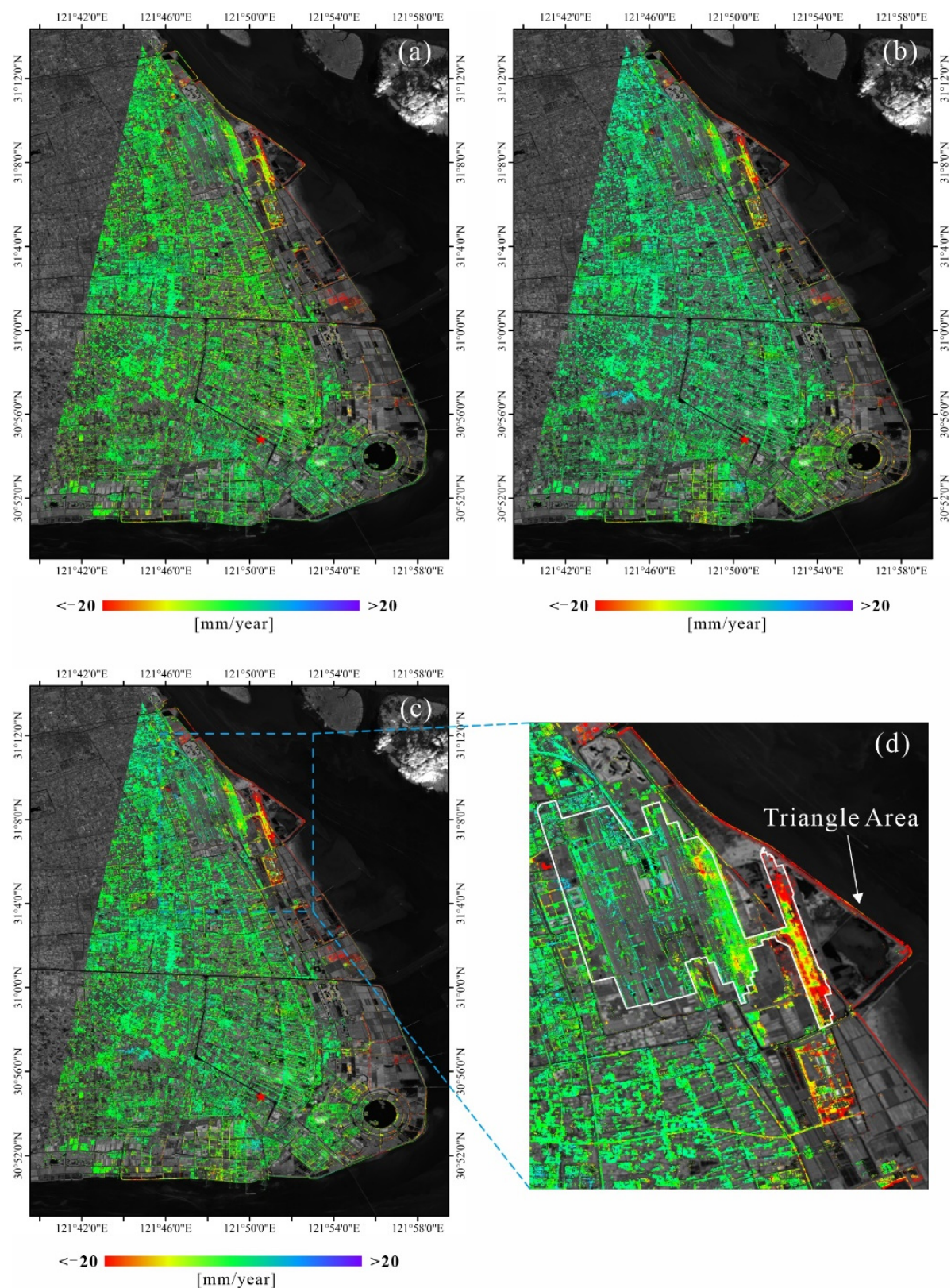

Figure 9. (a) Map of geocoded mean LOS deformation velocity calculated with the S-1A ground deformation time-series, from March 2018 to August 2021. (b) Map of geocoded mean LOS deformation velocity calculated with the CSK ground deformation time-series, from March 2018 to June 2021. (c) Map of geocoded mean deformation velocity in the Up-Down direction from 2018 to 2021 derives from two SAR datasets in the ascending and descending paths, respectively. The red star represents the location of the reference pixel. (d) Zoom of the area within the blue box shown in (c). The white polygon highlights Pudong Airport. 



Figure 10. (a) The geocoded density map of high-coherent objects. (b) Seawall heights for the selected 40 segments. Note that the density of high-coherent objects is measured as the number of high-coherent objects in the single geocoded $90 \times 90$-m grid.

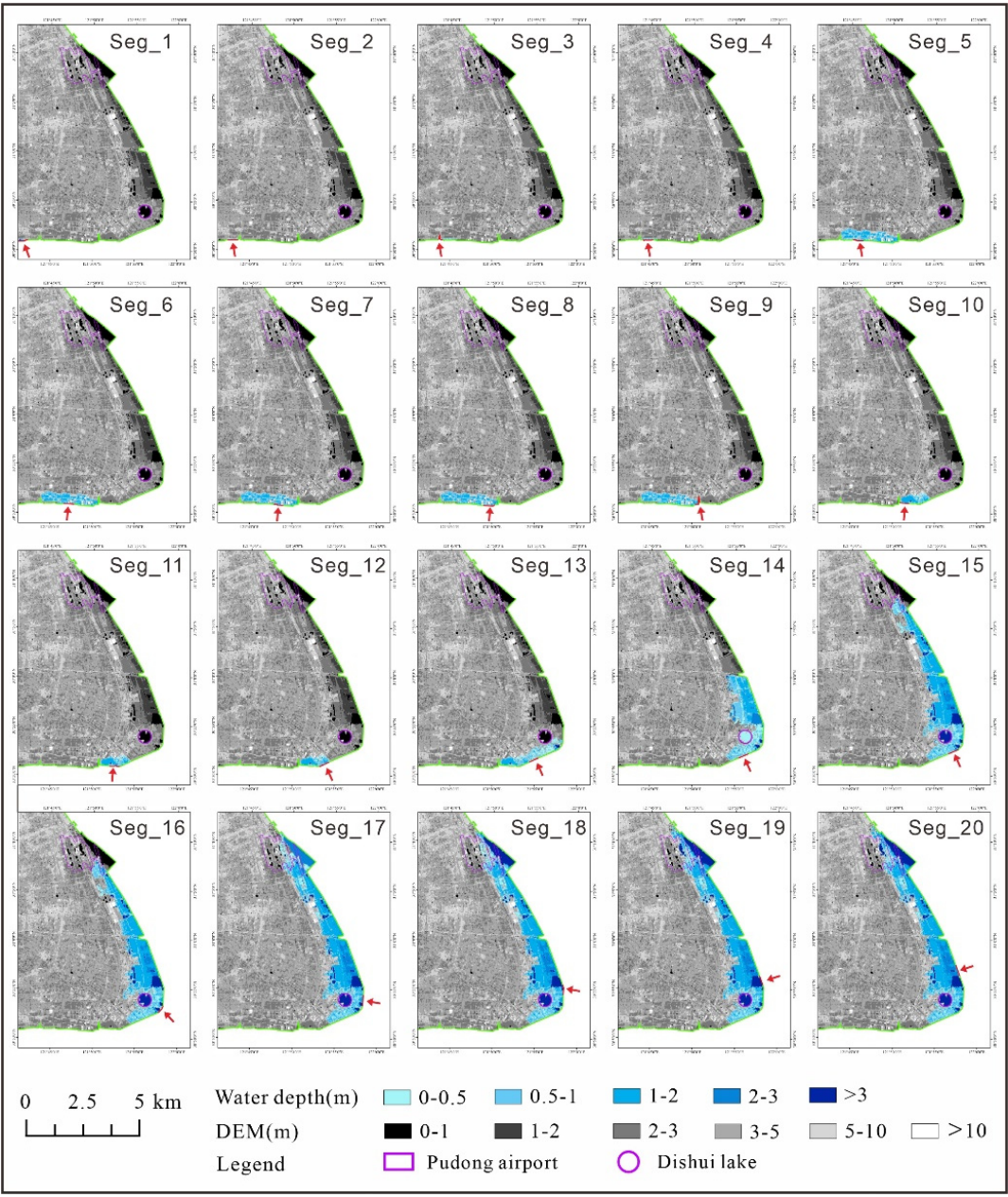

Figure 11. Simulated inundation scenarios for a 100-year return period flood in Shanghai. The section where each red arrow points is the location where the wave is assumed to overtop. 


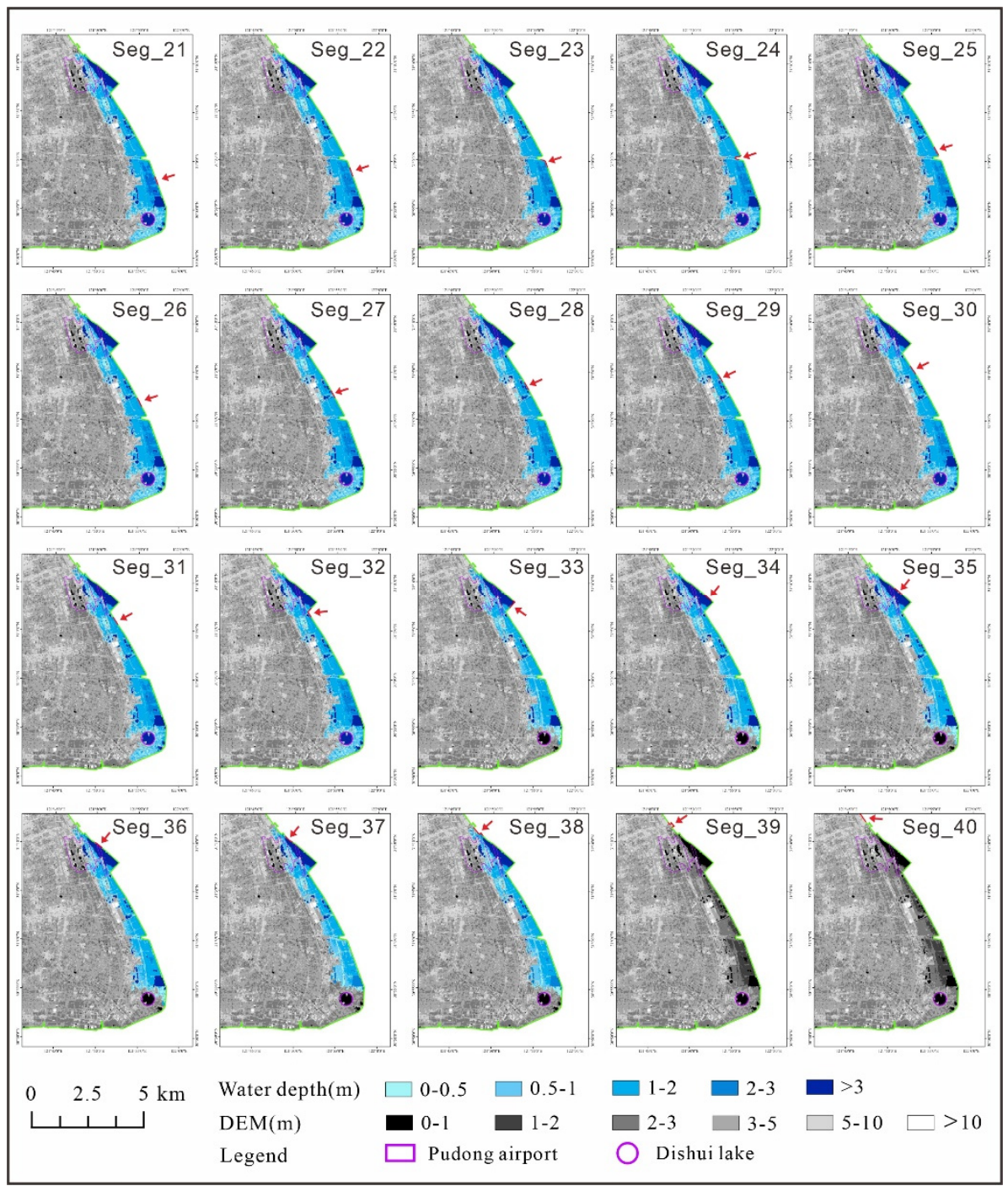

Figure 12. Simulated inundation scenarios for a 100-year return period flood in Shanghai. The section where each red arrow points is the location where the wave is assumed to overtop.

For segments 5 to 14 (Figures 9 and 10), the inundation areas were relatively low and distributed in a local region determined by the overtopping location. For segments 17 to 32, any failure would lead to extensive and continuous flooding along the coast from Pudong Airport to Dishui Lake. The deepest flooded regions $(>3 \mathrm{~m})$ were seen in a triangularshaped area on the northeast side of Pudong Airport and around Dishui Lake. This is because these regions have a near-zero elevation, and thus will be quickly inundated. We can easily assess the damage extent from the inundation maps by calculating the flooded area. However, the more important factor is that the effects on inhabitants are still unknown due to the uneven distribution of the population and buildings. Overall, land in eastern Shanghai is more vulnerable to seawater intrusion. This region was reclaimed from the ocean after 2000, and its average elevation is lower than southern Shanghai. However, this region is mainly composed of farmland, wetland, and unused land. In contrast, more built-up areas are in the flooded area within southern Shanghai (Figure 10a). Furthermore, as mentioned in Section 2.3.5, we utilized the $D_{P}$ to measure the density of buildings in a flooded region.

\subsubsection{Flood Risk Assessment of Wave Overtopping}

We derived from the considered 40 scenarios described in Section 3.4.2 a risk map (Figure 13a) that relates the probability of wave overtopping (worst case) with the impact 
on the ground in terms of high-coherent objects located in the simulated inundated regions. The simulations considered the seawall heights and their potential displacements ten years from now (2030) using the obtained DInSAR-driven ground displacement time series. The probability of overtopping was relatively high $(>7 \%)$ in segments 3 to 6 . For segments 5 to 9 , the density of high-coherent objects was more than twice that in other segments. The flooded domains were similar when overtopping occurred in segments 5 to 9 , as shown in Figure 11. In this area, although the inundation areas were not large, the density of high-coherent objects was the highest when compared with other coastal areas. We focused on critical segments 5 and 6, which had high probability and density. There are many kinds of industrial plants found in the inundation areas of segments 5 and 6 . Two ports (Luchaogang Port and Shanghai Southern Port) are also adjacent (see Figure 13b). The vertical deformations of the seawall were low for segments 5 and 6 . However, because the seawalls were built before 2000 and are lower than the eastern seawalls, the projected seawall height in 2030 is the lowest, which leads to a high probability of overtopping.


Figure 13. (a) The overtopping flood risk map for the selected 40 segments of the Shanghai seawalls. The $X$-axis shows the probability of overtopping, and $Y$-axis is the impact of a flood, measured as the density of high-coherent points affected by the flood. (b) Zoom-in view of southern Shanghai in Figure 10a. The purple polygon shows the density of high-coherent objects within the flooded areas for overtopping scenarios 5 and 6 . The coherent target density was calculated as the number of points in a $90 \times 90 \mathrm{~m}$ grid.

\section{Discussion}

The coastal reclamation areas of the twelve cities considered here were largest in Dalian $\left(634.38 \mathrm{~km}^{2}\right)$, followed by Ningbo $\left(451.13 \mathrm{~km}^{2}\right)$, Tangshan $\left(409.65 \mathrm{~km}^{2}\right)$, Yancheng 
$\left(407.93 \mathrm{~km}^{2}\right)$, Nantong $\left(374.21 \mathrm{~km}^{2}\right)$, and Tianjin $\left(246.25 \mathrm{~km}^{2}\right)$. Except for Ningbo, the other five cities were all located in the north of China. This result is consistent with Tian et al. [8] and Huang et al. [5], who found that from 1985 to 2010, more than $70 \%$ of coastal reclamation projects were implemented in northern China. In particular, two cities in Bohai Bay (Tangshan and Tianjin) have rapidly carried out reclamation projects in the past several decades up to 2015 [109]. We compared the delineated outlines of newly reclaimed land shown in Figure 3b,c with other studies for these two cites. The results over the same period, which were interpreted with Landsat images, showed highly similar patterns [6,12]. For the reclamation areas of the YRD, the high-intensity reclamation areas were mainly located on the coast of Yancheng and Nantong, the three islands in the Yangtze Estuary, southeastern Shanghai, and northern Ningbo $[2,7,16,110]$, in line with our results.

We have demonstrated here that the simple cross-comparison of InSAR-driven DEMs produced at different epochs can give valuable (global) information on changes at the regional scale. We addressed the potential of InSAR technology to create worldwide topography maps with impacts on the study of ocean-reclaimed lands. DEM-assisted analyses were performed to quantify the extent of regions over China affected by floods. Flood risk increases in newly ocean-reclaimed lands were investigated by calculating the flood percentage of the reclaimed area and the ratio of reclaimed area flood zones to the total flood zones. On one hand, from this perspective, using newly-released DEMs (e.g., TDX90) is valuable to have global (at regional scale) estimates of the flood risk in coastal environments [107]. On the other hand, the vertical accuracy (to the order of a few meters) of the available DEMs is typically not accurate enough to implement detailed (localized) analyses, and the lack of data in areas close to water bodies both represent serious challenges that must be considered when studying the relations between extreme flood events and the state of consolidation of the ocean-reclaimed lands after the end of reclamation procedures. Seaward reclamation induces extreme events to occur earlier, and decreases the process of water-level and water-velocity reduction [30]. Before land reclamation, extensive continuous tidal wetlands (e.g., salt marshes and mangroves) can provide efficient wave damping [111,112]. In our work, we followed and improved upon previous approaches $[29,94,113]$ in using global DEMs (i.e., TDX90) to map coastal inundation at middle-to-large spatial scales. The DEM-assisted differencing method can provide valuable information on coastal districts at medium-to-low resolutions. More accurate DEMs, derived from LiDAR (Light Detection and Ranging) missions can be determined to produce detailed spatially explicit inundation maps. However, LiDAR missions are costly. The generated DEMs have a limited spatial extent and result in time-consuming operations to run the hydrodynamic models and recover the inundated areas. The application of DInSAR technology allows us to easily estimate the extent of the areas to be potentially analyzed (e.g., EU Copernicus Sentinel-1 swaths are to the order of $100 \times 200 \mathrm{~km}$ ) and simultaneously perform detailed investigations over the critical areas previously identified by using simple DEM-assisted experiments. DInSAR-driven ground displacement time-series (with an accuracy of a few millimeters), in situ data (e.g., seawall heights), and other ancillary data (e.g., the seawater level) can jointly be used to evaluate the risk of flooding at the local scale.

Our work provides a general overview of the capabilities of InSAR technologies at both regional (using at most DEM-assisted methods) and local scales (using DInSAR-driven displacement maps) to obtain updated space-time information changes that have occurred over a set of coherent objects located in ocean-reclaimed lands. In relation to previous InSAR studies performed in the Shanghai area [45,55,114-117], this work delineates a strategy to evaluate the risk maps of potential extreme flood events by considering the worst-case scenario that some of the barriers (seawall sectors) could fail due to wave action and be subsequently destroyed during an extreme event. To this aim, both the probabilities of wave overtopping and the impact of the potential inundations in the areas near the Shanghai coastline have been estimated. 


\section{Conclusions}

This study analyzed flood risks in the coastal cities of China that have experienced significant land reclamation. First, we used a DEM-based method to analyze the coastal evolution and elevation changes in newly reclaimed regions on a regional scale. We provide statistics of the reclamation areas related to twelve high intensity reclaimed cities and the ratio of reclamation area to the total administrative area. Results show that, in total, $3167.6 \mathrm{~km}^{2}$ of coastal land has been reclaimed in these cities. Among them, there are six cities with a reclamation area of more than $200 \mathrm{~km}^{2}$, mainly in northern China.

Moreover, we mapped the shape and hypsometry of newly reclaimed land and calculated the average elevation. Most of the ocean-reclaimed land belongs to the LECZ, which is expected to exacerbate flood risks. Quantitative analyses employ a simplified hydrodynamic model (LISFLOOD-FP) to map coastal inundation and calculate the flood zones in the whole city and reclaimed lands. A majority of the total flooded regions are in reclamation zones, and around $60 \%$ of the reclaimed land is likely to be flooded. These ratios for Yancheng, Nantong, Shanghai, and Wenzhou are more than $80 \%$.

Subsequently, we focused on a local scale analysis relevant to the area of Shanghai. The multi-temporal SBAS approach and the minimum acceleration multi-track DInSAR-based combination method [36,51] were applied to update ground displacement maps of the coastal area of Shanghai from 2018 to 2021. The density of high-coherent objects within inundation areas was used to estimate the flood impacts of over 40 simulated flooding scenarios. These results demonstrated that two southern segments (segments 5 and 6) had the highest flood risk among the 40 segments. This result can be attributed to the fact that these sections were built before 2000 and at a lower height than those in northern Shanghai. Although the subsidence of seawalls in the eastern parts of Shanghai is much higher, the future seawall height on the east coast is still higher than that in the south. In addition, compared with the original seawall height, the observed ground subsidence and its actual rate (from 2018 to 2021) has minor impacts on the probability of wave overtopping over time. For segments 5 and 6, the inundation areas were not the largest among the 40 scenarios. However, within their inundation regions, there were numerous buildings, factories, and two artificial ports, leading to a high density of high-coherent object distribution and showing a high coastal flood impact. Shanghai is a unique situation compared to the other cities considered here, and is the only place we considered seawall subsidence and wave overtopping using the InSAR method.

This investigation shows the potential of using InSAR technology in evaluating flood risk in low-lying coastal regions and delineates a strategy to quantify it. However, it also reveals some significant challenges such as the need to have accurate ground-truth and ancillary data at the scale of the single structures affected by potential inundations to have more reliable quantitative results on the inundated areas in real scenarios, instead of considering worst-case scenarios by relaxing some of the hypotheses regarding the on-going ground displacements and observed phenomena. Future studies will focus on other coastal populated cities, especially those with continuous artificial seawalls.

Author Contributions: Conceptualization, Q.Z., A.P. and M.T.; Data curation, M.T., C.Y. and Z.L.; Formal analysis, M.T., Q.Z. and A.P.; Funding acquisition, Q.Z. and A.P.; Investigation, M.T., F.F. and A.T.D.; Methodology, Q.Z., A.P. and M.T.; Project administration, Q.Z.; Resources, Q.Z.; Software, C.Y. and Z.L.; Supervision, A.P. and A.T.D.; Validation, Q.Z.; Visualization, M.T. and F.F.; Writing-original draft, M.T. and A.T.D.; Writing-review \& editing, Q.Z., A.P. and A.T.D. All authors have read and agreed to the published version of the manuscript.

Funding: This research was funded by the Natural Science Foundation of China, grant number 41801337; by the Research Grants of Science and Technology Commission of Shanghai Municipality, grant number 18ZR1410800; by the Fundamental Research Funds for the Central Universities of China; and by the Fund of the Director of the Key Laboratory of Geographic Information Science (Ministry of Education), East China Normal University, grant no. KLGIS2017C03.

Institutional Review Board Statement: Not applicable. 
Informed Consent Statement: Not applicable.

Acknowledgments: This work was supported by the Natural Science Foundation of China (\#41801337); the Research Grants of Science and Technology Commission of Shanghai Municipality through Project 18ZR1410800; the Fundamental Research Funds for the Central Universities of China; and the Fund of the Director of the Key Laboratory of Geographic Information Science (Ministry of Education), East China Normal University (grant no. KLGIS2017C03). This work was performed within the Dragon 4 ESA project ID 32294, entitled "Integrated analysis of the combined risk of ground subsidence, sea-level rise, and natural hazards in coastal delta regions", and the Dragon 5 ESA project ID 58351, entitled “Global Climate Change, Sea Level Rise, Extreme Events and Local Ground Subsidence Effects in Coastal and River Delta Regions through Novel and Integrated Remote Sensing Approaches (GREENISH)". The TanDEM-X DEM was obtained from the German Aerospace Center (DLR) data website. The SRTM DEM and Landsat images were obtained from the USGS Earth Explorer site. The Italian Space Agency provided us with the CSK images collected within the Dragon 4 project and the S-1A data were directly downloaded from the Alaska SAR facility Hub.

Conflicts of Interest: The authors declare no conflict of interest.

\section{References}

1. Li, Z.Q. Vulnerability of ecological environment in Leizhou Peninsula coastal zone and countermeasures. In Proceedings of the 2012 2nd International Conference on Remote Sensing, Environment and Transportation Engineering, Nanjing, China, 1-3 June 2012; pp. 1-4.

2. Wu, W.T.; Tian, B.; Zhou, Y.X.; Shu, M.Y.; Qi, X.Y.; Xu, W. The trends of coastal reclamation in China in the past three decades. Acta Ecol. Sin. 2016, 36, 5007-5016. (In Chinese) [CrossRef]

3. Sengupta, D.; Chen, R.; Meadows, M.E. Building beyond land: An overview of coastal land reclamation in 16 global megacities. Appl. Geogr. 2018, 90, 229-238. [CrossRef]

4. Xu, N.; Gong, P. Significant coastline changes in China during 1991-2015 tracked by Landsat data. Sci. Bull. 2018, 63, 883-886. [CrossRef]

5. Huang, C.; Zhang, C.; Liu, Q.; Wang, Z.; Li, H.; Liu, G. Land reclamation and risk assessment in the coastal zone of China from 2000 to 2010. Reg. Stud. Mar. Sci. 2020, 39, 101422. [CrossRef]

6. Chen, W.; Wang, D.; Huang, Y.; Chen, L.; Zhang, L.; Wei, X.; Sang, M.; Wang, F.; Liu, J.; Hu, B. Monitoring and analysis of coastal reclamation from 1995-2015 in Tianjin Binhai New Area, China. Sci. Rep. 2017, 7, 14336. [CrossRef]

7. Chu, Z.; Yang, X.; Feng, X.; Fan, D.; Li, Y.; Shen, X.; Miao, A. Temporal and spatial changes in coastline movement of the Yangtze delta during 1974-2010. J. Asian Earth Sci. 2013, 66, 166-174. [CrossRef]

8. Tian, B.; Wu, W.; Yang, Z.; Zhou, Y. Drivers, trends, and potential impacts of long-term coastal reclamation in China from 1985 to 2010. Estuar. Coast. Shelf Sci. 2016, 170, 83-90. [CrossRef]

9. Cihlar, J. Land cover mapping of large areas from satellites: Status and research priorities. Int. J. Remote Sens. 2000, 21, 1093-1114. [CrossRef]

10. Kustas, W.P.; Norman, J.M. Utilisation de la télédétection pour le suivi de l'évapotranspiration sur les terres. Hydrol. Sci. J. 1996, 41, 495-516. [CrossRef]

11. Hou, X.Y.; Wu, T.; Hou, W.; Chen, Q.; Wang, Y.D.; Yu, L.J. Characteristics of coastline changes in mainland China since the early 1940s. Sci. China Earth Sci. 2016, 59, 1791-1802. [CrossRef]

12. Wang, W.; Liu, H.; Li, Y.; Su, J. Development and management of land reclamation in China. Ocean Coast. Manag. 2014, 102, 415-425. [CrossRef]

13. $\mathrm{Wu}, \mathrm{X}$.; Liu, C.; Wu, G. Spatial-temporal analysis and stability investigation of coastline changes: A case study in Shenzhen, China. IEEE J. Sel. Top. Appl. Earth Obs. Remote Sens. 2018, 11, 45-56. [CrossRef]

14. Zhu, L.; Wu, J.; Xu, Z.; Xu, Y.; Lin, J.; Hu, R. Coastline movement and change along the Bohai Sea from 1987 to 2012. J. Appl. Remote Sens. 2014, 8, 083585. [CrossRef]

15. Li, J.; Ye, M.; Pu, R.; Liu, Y.; Guo, Q.; Feng, B.; Huang, R.; He, G. Spatiotemporal change patterns of coastlines in Zhejiang Province, China, over the last twenty-five years. Sustainability 2018, 10, 477. [CrossRef]

16. Wang, X.; Liu, Y.; Ling, F.; Liu, Y.; Fang, F. Spatio-temporal change detection of Ningbo coastline using landsat time-series images during 1976-2015. ISPRS Int. J. Geo-Inf. 2017, 6, 68. [CrossRef]

17. Liu, C.; Wu, X.; Cao, X.; Wu, G. Analysis of Coastline Changes and the Socio-economic Driving Mechanisms in Shenzhen, China. Mar. Geod. 2017, 40, 378-403. [CrossRef]

18. Gens, R. Remote sensing of coastlines: Detection, extraction and monitoring. Int. J. Remote Sens. 2010, 31, 1819-1836. [CrossRef]

19. Wu, Y.; Liu, Z. Research progress on methods of automatic coastline extraction based on remote sensing images. J. Remote Sens. 2019, 23, 582-602. [CrossRef]

20. Kuleli, T.; Guneroglu, A.; Karsli, F.; Dihkan, M. Automatic detection of shoreline change on coastal Ramsar wetlands of Turkey. Ocean Eng. 2011, 38, 1141-1149. [CrossRef] 
21. Yasir, M.; Sheng, H.; Fan, H.; Nazir, S.; Niang, A.J.; Salauddin, M.; Khan, S. Automatic Coastline Extraction and Changes Analysis Using Remote Sensing and GIS Technology. IEEE Access 2020, 8, 180156-180170. [CrossRef]

22. Ge, X.; Sun, X.; Liu, Z. Object-oriented coastline classification and extraction from remote sensing imagery. In Proceedings of the Remote Sensing of the Environment: 18th National Symposium on Remote Sensing of China, Wuhan, China, 20-23 October 2012; Volume 9158, p. 91580M.

23. Zhu, Z.; Tang, Y.; Hu, J.; An, M. Coastline Extraction from High-Resolution Multispectral Images by Integrating Prior Edge Information with Active Contour Model. IEEE J. Sel. Top. Appl. Earth Obs. Remote Sens. 2019, 12, 4099-4109. [CrossRef]

24. Massonnet, D.; Feigl, K.L. Radar interferometry and its application to changes in the earth's surface. Rev. Geophys. 1998, 36, 441-500. [CrossRef]

25. Hennig, T.A.; Kretsch, J.L.; Pessagno, C.J.; Salamonowicz, P.H.; Stein, W.L. The shuttle radar topography mission. In Proceedings of the Digital Earth Moving. First International Symposium, DEM 2001, Manno, Switzerland, 5-7 September 2001 ; pp. 65-77.

26. Deutsches Zentrum für Luft-und Raumfahrt. EOC Geoservice. Available online: https://download.geoservice.dlr.de/TDM90/ (accessed on 3 July 2021).

27. Fang, J.; Lincke, D.; Brown, S.; Nicholls, R.J.; Wolff, C.; Merkens, J.L.; Hinkel, J.; Vafeidis, A.T.; Shi, P.; Liu, M. Coastal flood risks in China through the 21st century-An application of DIVA. Sci. Total Environ. 2020, 704, 135311. [CrossRef]

28. Wu, S.Y.; Yarnal, B.; Fisher, A. Vulnerability of coastal communities to sea-level rise: A case study of Cape May County, New Jersey, USA. Clim. Res. 2002, 22, 255-270. [CrossRef]

29. Yin, J.; Xu, S.; Wang, J.; Zhong, H.; Hu, Y.; Yin, Z.; Wang, K.; Zhang, X. Vulnerability assessment of combined impacts of sea level rise and coastal flooding for China's coastal region using remote sensing and GIS. In Proceedings of the 18th International Conference on Geoinformatics, Beijing, China, 18-20 June 2010; pp. 3-6.

30. Du, M.; Hou, Y.; Guo, Y.; Wang, K. Numerical Simulation and Risk Analysis of Coastal Inundation in Land Reclamation Areas: A Case Study of the Pearl River Estuary. J. Ocean Univ. China 2020, 19, 1221-1234. [CrossRef]

31. Izaguirre, C.; Losada, I.J.; Camus, P.; Vigh, J.L.; Stenek, V. Climate change risk to global port operations. Nat. Clim. Chang. 2020, 11, 14-20. [CrossRef]

32. Papagiannakis, A.; Ntafos, K. Impact Assessment of Climate Change on Coastal Transport Systems in the Greater Thessaloniki Area. In Proceedings of the 5th Conference on Sustainable Urban Mobility, Virtual CSUM2020, Skiathos Island, Greece, 17-19 June 2020; Nathanail, E.G., Adamos, G., Karakikes, I., Eds.; Springer International Publishing: Berlin/Heidelberg, Germany, 2020; pp. 751-759.

33. Crosetto, M.; Crippa, B.; Biescas, E. Early detection and in-depth analysis of deformation phenomena by radar interferometry. Eng. Geol. 2005, 79, 81-91. [CrossRef]

34. Usai, S. A least squares database approach for SAR interferometric data. IEEE Trans. Geosci. Remote Sens. 2003, 41, 753-760. [CrossRef]

35. Werner, C.; Wegmüller, U.; Strozzi, T.; Wiesmann, A. Interferometric Point Target Analysis for Deformation Mapping. In Proceedings of the International Geoscience and Remote Sensing Symposium (IGARSS), Toulouse, France, 21-25 July 2003 Volume 7, pp. 4362-4364.

36. Berardino, P.; Fornaro, G.; Lanari, R.; Sansosti, E. A new algorithm for surface deformation monitoring based on small baseline differential SAR interferograms. IEEE Trans. Geosci. Remote Sens. 2002, 40, 2375-2383. [CrossRef]

37. Mora, O.; Mallorqui, J.J.; Broquetas, A. Linear and nonlinear terrain deformation maps from a reduced set of interferometric SAR images. IEEE Trans. Geosci. Remote Sens. 2003, 41, 2243-2253. [CrossRef]

38. Hooper, A.; Zebker, H.; Segall, P.; Kampes, B. A new method for measuring deformation on volcanoes and other natural terrains using InSAR persistent scatterers. Geophys. Res. Lett. 2004, 31, 1-5. [CrossRef]

39. Ferretti, A.; Prati, C.; Rocca, F. Permanent scatterers in SAR interferometry. IEEE Trans. Geosci. Remote Sens. 2001, 39, 8-20. [CrossRef]

40. Hu, B.; Chen, J.; Zhang, X. Monitoring the land subsidence area in a coastal urban area with InSAR and GNSS. Sensors 2019, 19, 181. [CrossRef] [PubMed]

41. Wang, H.; Wright, T.J.; Yu, Y.; Lin, H.; Jiang, L.; Li, C.; Qiu, G. InSAR reveals coastal subsidence in the Pearl River Delta, China. Geophys. J. Int. 2012, 191, 1119-1128. [CrossRef]

42. Xu, B.; Feng, G.; Li, Z.; Wang, Q.; Wang, C.; Xie, R. Coastal subsidence monitoring associated with land reclamation using the point target based SBAS-InSAR method: A case study of Shenzhen, China. Remote Sens. 2016, 8, 652. [CrossRef]

43. Yu, Q.; Wang, Q.; Yan, X.; Yang, T.; Song, S.; Yao, M.; Zhou, K.; Huang, X. Ground deformation of the Chongming East Shoal reclamation area in Shanghai based on sbas-insar and laboratory tests. Remote Sens. 2020, 12, 16. [CrossRef]

44. Zhuo, G.; Dai, K.; Huang, H.; Li, S.; Shi, X.; Feng, Y.; Li, T.; Dong, X.; Deng, J. Evaluating potential ground subsidence geo-hazard of Xiamen Xiang'an new airport on reclaimed land by SAR interferometry. Sustainability 2020, 12, 6991. [CrossRef]

45. Jiang, Y.; Liao, M.; Wang, H.; Zhang, L.; Balz, T. Deformation monitoring and analysis of the geological environment of Pudong International Airport with persistent scatterer SAR interferometry. Remote Sens. 2016, 8, 1021. [CrossRef]

46. Yang, M.; Yang, T.; Zhang, L.; Lin, J.; Qin, X.; Liao, M. Spatio-temporal characterization of a reclamation settlement in the Shanghai coastal area with time series analyses of X-, C-, and L-band SAR datasets. Remote Sens. 2018, 10, 329. [CrossRef]

47. Wang, F.; Li, J.; Shi, P.; Shang, Z.; Li, Y.; Wang, H. The impact of sea-level rise on the coast of Tianjin-Hebei, China. China Geol. 2019, 2, 26-39. [CrossRef] 
48. Chengcheng, S.; Mengya, L.; Jun, W.; Shiyuan, X.; Zhenlou, C. Simulation of typhoon storm surge impacts in Shanghai based on storm surge scenarios and disaster prevention measures. Prog. Geogr. 2014, 33, 1693-1703. (In Chinese) [CrossRef]

49. Wang, J.; Gao, W.; Xu, S.; Yu, L. Evaluation of the combined risk of sea level rise, land subsidence, and storm surges on the coastal areas of Shanghai, China. Clim. Change 2012, 115, 537-558. [CrossRef]

50. Shirzaei, M. A Seamless Multitrack Multitemporal InSAR Algorithm. Geochemistry Geophys. Geosystems 2015, 18, 1541-1576. [CrossRef]

51. Pepe, A.; Solaro, G.; Calo, F.; Dema, C. A Minimum Acceleration Approach for the Retrieval of Multiplatform InSAR Deformation Time Series. IEEE J. Sel. Top. Appl. Earth Obs. Remote Sens. 2016, 9, 3883-3898. [CrossRef]

52. Samsonov, S.; d'Oreye, N. Multidimensional time-series analysis of ground deformation from multiple InSAR data sets applied to Virunga Volcanic Province. Geophys. J. Int. 2012, 191, 1095-1108. [CrossRef]

53. Hu, J.; Ding, X.; Li, Z.; Zhu, J.; Sun, Q.; Zhang, L. Kalman-Filter-Based Approach for Multisensor, Multitrack, and Multitemporal InSAR. IEEE Trans. Geosci. Remote Sens. 2013, 51, 4226-4239. [CrossRef]

54. Yao, G.; Ke, C.Q.; Zhang, J.; Lu, Y.; Zhao, J.; Lee, H. Surface deformation monitoring of Shanghai based on ENVISAT ASAR and Sentinel-1A data. Environ. Earth Sci. 2019, 78, 225. [CrossRef]

55. Wang, W. Detection of land subsidence of Shanghai: A research based on differential SAR interferometry. In Proceedings of the Earth Observing Missions and Sensors-Development, Implementation, and Characterization III, Beijing, China, 13-15 October 2014; Volume 9264, p. 92641.

56. Lei, M.; Wang, Q.; Liu, X.; Xu, B.; Zhang, H. Influence of ocean tidal loading on InSAR offshore areas deformation monitoring. Geod. Geodyn. 2017, 8, 70-76. [CrossRef]

57. Bates, P.D.; De Roo, A.P.J. A simple raster-based model for flood inundation simulation. J. Hydrol. 2000, 236, 54-77. [CrossRef]

58. Bates, P.D.; Horritt, M.S.; Fewtrell, T.J. A simple inertial formulation of the shallow water equations for efficient two-dimensional flood inundation modelling. J. Hydrol. 2010, 387, 33-45. [CrossRef]

59. Muis, S.; Verlaan, M.; Winsemius, H.C.; Aerts, J.C.J.H.; Ward, P.J. A global reanalysis of storm surges and extreme sea levels. Nat. Commun. 2016, 7, 11969. [CrossRef] [PubMed]

60. Jones, M.C.; Marchand, É. A (non-central) chi-squared mixture of non-central chi-squareds is (non-central) chi-squared and related results, corollaries and applications. Stat 2021, 10, e398. [CrossRef]

61. National Bureau of Statistics of China. National Data. Available online: https:/ / data.stats.gov.cn/english/easyquery.htm?cn=E0 103 (accessed on 3 July 2021).

62. State Oceanic Administration of China (SOA). China Marine Statistical Yearbook (2016); China Statistics Press: Beijing, China, 2017.

63. United Nations. World Urbanization Prospects: The 2018 Revision; United Nations: New York, NY, USA, 2019; ISBN 978-92-1-148319-2.

64. Ma, T.; Li, X.; Bai, J.; Cui, B. Impacts of Coastal Reclamation on Natural Wetlands in Large River Deltas in China. Chinese Geogr. Sci. 2019, 29, 640-651. [CrossRef]

65. Qiao, G.; Mi, H.; Wang, W.; Tong, X.; Li, Z.; Li, T.; Liu, S.; Hong, Y. 55-year (1960-2015) spatiotemporal shoreline change analysis using historical DISP and Landsat time series data in Shanghai. Int. J. Appl. Earth Obs. Geoinf. 2018, 68, 238-251. [CrossRef]

66. Pei, Y.; Liao, M.; Wang, T.; Zhang, L. Monitoring the stability of levees with time-series ENVISAT ASAR images. In Proceedings of the Fringe 2011 Workshop, Frascati, Italy, 19-23 September 2011; pp. 393-397.

67. Liu, Z.; Zhu, J.; Fu, H.; Zhou, C.; Zuo, T. Evaluation of the vertical accuracy of open global dems over steep terrain regions using icesat data: A case study over hunan province, china. Sensors 2020, 20, 4865. [CrossRef] [PubMed]

68. Wessel, B. TanDEM-X Ground Segment DEM Products Specification Document; TanDEM-X Science Server: Oberpfaffenhofen, Germany, 2018.

69. Rodríguez, E.; Morris, C.S.; Belz, J.E. A global assessment of the SRTM performance. Photogramm. Eng. Remote Sensing 2006, 72, 249-260. [CrossRef]

70. Meyer, D.J.; Tachikawa, T.; Abrams, M.; Crippen, R.; Krieger, T.; Gesch, D.; Carabajal, C. Summary of the Validation of the Second Version of the Aster Gdem. Int. Arch. Photogramm. Remote Sens. Spat. Inf. Sci. 2012, 39, 291-293. [CrossRef]

71. Tadono, T.; Nagai, H.; Ishida, H.; Oda, F.; Naito, S.; Minakawa, K.; Iwamoto, H. Generation of the 30 M-MESH global digital surface model by alos prism. Int. Arch. Photogramm. Remote Sens. Spat. Inf. Sci. 2016, 41, 157-162. [CrossRef]

72. Hawker, L.; Neal, J.; Bates, P. Accuracy assessment of the TanDEM-X 90 Digital Elevation Model for selected floodplain sites Remote Sens. Environ. 2019, 232, 111319. [CrossRef]

73. Hooper, A.; Bekaert, D.; Spaans, K.; Arikan, M. Recent advances in SAR interferometry time series analysis for measuring crustal deformation. Tectonophysics 2012, 514-517, 1-13. [CrossRef]

74. Hu, H.; Zhan, Y. DEM generated from InSAR in mountainous terrain and its accuracy analysis. In Proceedings of the PIAGENG 2010: Photonics and Imaging for Agricultural Engineering, Qingdao, China, 25-26 December 2011; Volume 7752, p. 77521F.

75. Zhang, W.; Wang, W.; Chen, L. Constructing DEM Based on InSAR and the Relationship between InSAR DEM's Precision and Terrain Factors. In Proceedings of the International Conference on Future Energy, Environment, and Materials (FEEM), Hong Kong, China, 12-13 April 2012; Volume 16, pp. 184-189.

76. Massonnet, D.; Rossi, M.; Carmona, C.; Adragna, F.; Peltzer, G.; Feigl, K.; Rabaute, T. The displacement field of the Landers earthquake mapped by radar interferometry. Nature 1993, 364, 138-142. [CrossRef]

77. Bu, R.; Rosen, P.A.; Fielding, E.J. Synthetic aperture radar interferometry to measure Earth's surface topography and its deformation. Annu. Rev. Earth Planet. Sci. 2000, 28, 169-209. [CrossRef] 
78. Fialko, Y.; Simons, M.; Agnew, D. The complete (3-D) surface displacement field in the epicentral area of the $1999 \mathrm{M}(\mathrm{w}) 7.1 \mathrm{Hector}$ Mine earthquake, California, from space geodetic observations. Geophys. Res. Lett. 2001, 28, 3063-3066. [CrossRef]

79. Peltzer, G.; Rosen, P. Surface Displacement of the 17 May 1993 Eureka Valley, California, Earthquake Observed by SAR Interferometry. Science 1995, 268, 1333-1336. [CrossRef]

80. Hooper, A.J. A multi-temporal InSAR method incorporating both persistent scatterer and small baseline approaches. Geophys. Res. Lett. 2008, 35, 1-5. [CrossRef]

81. Ferretti, A.; Prati, C.; Rocca, F. Nonlinear subsidence rate estimation using permanent scatterers in differential SAR interferometry. IEEE Trans. Geosci. Remote Sens. 2000, 38, 2202-2212. [CrossRef]

82. Zebker, H.A.; Villasenor, J. Decorrelation in interferometric radar echoes. IEEE Trans. Geosci. Remote Sens. 1992, 30, 950-959. [CrossRef]

83. Pepe, A.; Lanari, R. On the extension of the minimum cost flow algorithm for phase unwrapping of multitemporal differential SAR interferograms. IEEE Trans. Geosci. Remote Sens. 2006, 44, 2374-2383. [CrossRef]

84. Yang, Y.; Pepe, A.; Manzo, M.; Casu, F.; Lanari, R. A region-growing technique to improve multi-temporal DInSAR interferogram phase unwrapping performance. Remote Sens. Lett. 2013, 4, 988-997. [CrossRef]

85. Chen, J.; Wu, J.; Zhang, L.; Zou, J.; Liu, G.; Zhang, R.; Yu, B. Deformation trend extraction based on multi-temporal insar in shanghai. Remote Sens. 2013, 5, 1774-1786. [CrossRef]

86. Casu, F.; Manzo, M.; Lanari, R. A quantitative assessment of the SBAS algorithm performance for surface deformation retrieval from DInSAR data. Remote Sens. Environ. 2006, 102, 195-210. [CrossRef]

87. Zhang, Y.; Liu, Y.; Jin, M.; Jing, Y.; Liu, Y.; Liu, Y.; Sun, W.; Wei, J.; Chen, Y. Monitoring land subsidence in wuhan city (China) using the SBAS-INSAR method with radarsat-2 imagery data. Sensors 2019, 19, 743. [CrossRef] [PubMed]

88. Pepe, A.; Calò, F. A review of interferometric synthetic aperture RADAR (InSAR) multi-track approaches for the retrieval of Earth's Surface displacements. Appl. Sci. 2017, 7, 1264. [CrossRef]

89. Himmelstoss, E.A.; Henderson, R.E.; Kratzmann, M.G.; Farris, A.S. Digital Shoreline Analysis System (DSAS) Version 5.0 User Guide; U.S. Geological Survey: Reston, VA, USA, 2018.

90. Bates, P.D.; Dawson, R.J.; Hall, J.W.; Horritt, M.S.; Nicholls, R.J.; Wicks, J.; Ali Mohamed Hassan, M.A. Simplified two-dimensional numerical modelling of coastal flooding and example applications. Coast. Eng. 2005, 52, 793-810. [CrossRef]

91. Lewis, M.; Horsburgh, K.; Bates, P.; Smith, R. Quantifying the uncertainty in future coastal flood risk estimates for the U.K. J. Coast. Res. 2011, 27, 870-881. [CrossRef]

92. Christie, E.K.; Spencer, T.; Owen, D.; McIvor, A.L.; Möller, I.; Viavattene, C. Regional coastal flood risk assessment for a tidally dominant, natural coastal setting: North Norfolk, southern North Sea. Coast. Eng. 2018, 134, 177-190. [CrossRef]

93. Duo, E.; Fernández-Montblanc, T.; Armaroli, C. Semi-probabilistic coastal flood impact analysis: From deterministic hazards to multi-damage model impacts. Environ. Int. 2020, 143, 105884. [CrossRef]

94. Irawan, A.M.; Marfai, M.A.; Nugraheni, I.R.; Gustono, S.T.; Rejeki, H.A.; Widodo, A.; Mahmudiah, R.R.; Faridatunnisa, M. Comparison between averaged and localised subsidence measurements for coastal floods projection in 2050 Semarang, Indonesia. Urban Clim. 2021, 35, 100760. [CrossRef]

95. Muis, S.; Verlaan, M.; Nicholls, R.J.; Brown, S.; Hinkel, J.; Lincke, D.; Vafeidis, A.T.; Scussolini, P.; Winsemius, H.C.; Ward, P.J. A comparison of two global datasets of extreme sea levels and resulting flood exposure. Earth's Futur. 2017, 5, 379-392. [CrossRef]

96. Zhu, S.; Dai, Q.; Zhao, B.; Shao, J. Assessment of Population Exposure to Urban Flood at the Building Scale. Water 2020, 12, 3253. [CrossRef]

97. Rahimzadeh, O.; Bahremand, A.; Noura, N.; Mukolwe, M. Evaluating flood extent mapping of two hydraulic models, 1D HEC-RAS and 2D LISFLOOD-FP in comparison with aerial imagery observations in Gorgan flood plain, Iran. Nat. Resour. Model. 2019, 32, e12214. [CrossRef]

98. Sosa, J.; Sampson, C.; Smith, A.; Neal, J.; Bates, P. A toolbox to quickly prepare flood inundation models for LISFLOOD-FP simulations. Environ. Model. Softw. 2020, 123, 104561. [CrossRef]

99. Yang, X.; Hu, X.; Li, Z. The conditional risk probability-based seawall height design method. Int. J. Nav. Archit. Ocean Eng. 2015, 7, 1007-1019. [CrossRef]

100. Chen, Y.; Shi, Y.; Li, B.; Yu, J. Seawall subsidence in Shanghai: Characteristics and driving mechanisms. Mar. Geol. Quat. Geol. 2016, 36, 71-78. [CrossRef]

101. Lian, J.J.; Xu, K.; Ma, C. Joint impact of rainfall and tidal level on flood risk in a coastal city with a complex river network: A case study of Fuzhou City, China. Hydrol. Earth Syst. Sci. 2013, 17, 679-689. [CrossRef]

102. Gumbel, E.J. Statistics of Extremes; Columbia University Press: New York, NY, USA, 1958; ISBN 9780231891318.

103. Jenkinson, A.F. The frequency distribution of the annual maximum (or minimum) values of meteorological elements. $Q$. J. $R$. Meteorol. Soc. 1955, 81, 158-171. [CrossRef]

104. Graff, J. An investigation of the frequency distributions of annual sea level maxima at ports around Great Britain. Estuar. Coast. Shelf Sci. 1981, 12, 389-449. [CrossRef]

105. Zhao, Q.; Ma, G.; Wang, Q.; Yang, T.; Liu, M.; Gao, W.; Falabella, F.; Mastro, P.; Pepe, A. Generation of long-term InSAR ground displacement time-series through a novel multi-sensor data merging technique: The case study of the Shanghai coastal area. ISPRS J. Photogramm. Remote Sens. 2019, 154, 10-27. [CrossRef] 
106. Falabella, F.; Serio, C.; Masiello, G.; Zhao, Q.; Pepe, A. A Multigrid InSAR Technique for Joint Analyses at Single-Look and Multi-Look Scales. IEEE Geosci. Remote Sens. Lett. 2021, 19, 4014905. [CrossRef]

107. McGranahan, G.; Balk, D.; Anderson, B. The rising tide: Assessing the risks of climate change and human settlements in low elevation coastal zones. Environ. Urban. 2007, 19, 17-37. [CrossRef]

108. Wu, L.; Wang, J.; Zhou, J.; Yang, T.; Yan, X.; Zhao, Y.; Ye, Z.; Xu, N. Multi-scale geotechnical features of dredger fills and subsidence risk evaluation in reclaimed land using BN. Mar. Georesources Geotechnol. 2020, 38, 947-969. [CrossRef]

109. Martín-Antón, M.; Negro, V.; Del Campo, J.M.; López-Gutiérrez, J.S.; Esteban, M.D. Review of coastal land reclamation situation in the world. J. Coast. Res. 2016, 1, 667-671. [CrossRef]

110. Chen, L.; Ren, C.; Zhang, B.; Li, L.; Wang, Z.; Song, K. Spatiotemporal Dynamics of Coastal Wetlands and Reclamation in the Yangtze Estuary During Past 50 Years (1960s-2015). Chinese Geogr. Sci. 2018, 28, 386-399. [CrossRef]

111. Zhang, M.; Dai, Z.; Bouma, T.J.; Bricker, J.; Townend, I.; Wen, J.; Zhao, T.; Cai, H. Tidal-flat reclamation aggravates potential risk from storm impacts. Coast. Eng. 2021, 166, 103868. [CrossRef]

112. Van Coppenolle, R.; Schwarz, C.; Temmerman, S. Contribution of Mangroves and Salt Marshes to Nature-Based Mitigation of Coastal Flood Risks in Major Deltas of the World. Estuaries Coasts 2018, 41, 1699-1711. [CrossRef]

113. Yin, J.; Zhao, Q.; Yu, D.; Lin, N.; Kubanek, J.; Ma, G.; Liu, M.; Pepe, A. Long-term flood-hazard modeling for coastal areas using InSAR measurements and a hydrodynamic model: The case study of Lingang New City, Shanghai. J. Hydrol. 2019, 571, 593-604. [CrossRef]

114. Dai, K.; Liu, G.; Li, Z.; Li, T.; Yu, B.; Wang, X.; Singleton, A. Extracting vertical displacement rates in Shanghai (China) with multi-platform SAR images. Remote Sens. 2015, 7, 9542-9562. [CrossRef]

115. Qin, X.; Yang, T.; Yang, M.; Zhang, L.; Liao, M. Health diagnosis of major transportation infrastructures in Shanghai metropolis using high- resolution persistent scatterer interferometry. Sensors 2017, 17, 2770. [CrossRef]

116. Dong, S.; Samsonov, S.; Yin, H.; Ye, S.; Cao, Y. Time-series analysis of subsidence associated with rapid urbanization in Shanghai, China measured with SBAS InSAR method. Environ. Earth Sci. 2014, 72, 677-691. [CrossRef]

117. Hui, L.; Fulong, C.; Qing, Z. Land deformation monitoring using coherent target-neighbourhood networking method combined with polarimetric information: A case study of Shanghai, China. Int. J. Remote Sens. 2011, 32, 2395-2407. [CrossRef] 